University of Rhode Island

DigitalCommons@URI

Open Access Master's Theses

1997

\title{
Enhancing Social Service to At-Risk Children
}

James Paglia

University of Rhode Island

Follow this and additional works at: https://digitalcommons.uri.edu/theses

\section{Recommended Citation}

Paglia, James, "Enhancing Social Service to At-Risk Children" (1997). Open Access Master's Theses.

Paper 728.

https://digitalcommons.uri.edu/theses/728

This Thesis is brought to you for free and open access by DigitalCommons@URI. It has been accepted for inclusion in Open Access Master's Theses by an authorized administrator of DigitalCommons@URI. For more information, please contact digitalcommons-group@uri.edu. 


\title{
ENHANCING SOCIAL SERVICE TO AT-RISK CHILDREN
}

\author{
BY \\ JAMES PAGLIA
}

\section{A RESEARCH PROJECT SUBMITTED IN PARTIAL FULFILLMENT OF THE REQUIREMENTS FOR THE DEGREE OF MASTER OF COMMUNITY PLANNING}


MASTER OF COMMUNITY PLANNING

RESEARCH PROJECT

OF

JAMES PAGLIA

Approved:

Major Professor

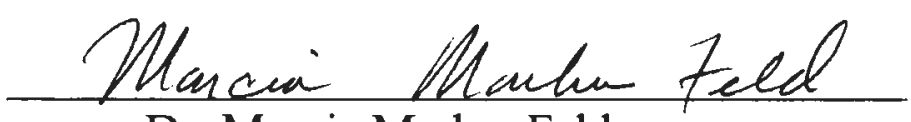

Dr. Marcia Marker Feld

Acknowledged:
Director of Graduate Studies low lua Dr. Farhad Atash 


\section{$\underline{\text { ABSTRACT }}$}

The Children, Youth \& Families Issue Group, part of the University of Rhode Island's Cooperative Extension Service, has provided education outreach and technical assistance to community based social service providers since 1990 . In an effort to enhance the effectiveness of the programming which they provide the group initiated a research project designed to illuminate strategies for increasing the effectiveness of community-based service provision. This study uses the theory of developmental contextualism as presented by Dr. Richard Lerner to suggest ways in which service providers can enhance their effectiveness by understanding the particular context of their community.

The study focuses on two Rhode Island communities which were identified as being at-risk by Cooperative Extension; these communities are Pawtucket and West Warwick, Rhode Island. Demographic data pertaining to these communities as well as a sample of social services available are considered. An analysis of the service provided in each community is also presented. Recommendations for enhancing community service provision are based on the theory developmental contextualism applied as the development-in-context evaluation (DICE) model by Dr. Richard Lerner. 


\section{ACKNOWLEDGMENTS}

This study would not have been possible if not for the insight and expertise of Marilyn Martin of the Children, Youth \& Families Issue Group. Special thanks also goes out to Dr. Marcia Marker Feld and Dr. Howard Foster who patiently advised me during this research. 


\section{TABLE OF CONTENTS}

Chapter One: Introduction. Page I

Chapter Two: Demographics..................................................... Page 12

Chapter Three: Developmental Contexiualism. Page 27

Chapter Four: Community Services.............................................. Page 34

Chapter Five: Recommendations................................................ Page 46 


\section{TABLE OF ILLUSTRATIONS}

Table 1: Population by Race, Pawtucket, RI

Page 13

Map 1: Location of Pawtucket, RI

Page 13a

Table 2: Population by Race, West Warwick, RI

Page 14

Map 2: Location of West Warwick, RI

Page 14a

Table 3: Age Distribution: Pawtucket \& W. Warwick

Page 15

Table 4: Education-Persons Over 25, 1990

Page 16

Table 5: Household Income: Pawtucket \& W. Warwick, 1990

Page 16

Table 6: Family Income: Pawtucket \& W. Warwick, 1990

Page 17

Table 7: Race of Householder: Pawtucket \& W. Warwick

Page 18

Table 8: Child Population, 1990

Page 18

Table 9: Children in Poverty, 1990

Page 19

Table 10: Living Arrangements of Children in Families, 1990

Page 19

Table 11: Births to Teenage Mothers, 1988-92

Page 20

Table 12: High School Graduation Rate, 1994

Page 21

Table 13: Children Enrolled in Headstart, 1995

Page 22

Table 14: 16-19 Year Old's Not in School and Not Working

Page 22

Table 15: Children Receiving Public Assistance

Page 23

Table 16: Women, Infants Receiving W.I.C., 1995

Page 24

Table 17: Children Receiving School Breakfast, 1995

Page 24

Map 3: Location of Community Services, Pawtucket

Page 36a 


\section{TABLE OF ILLUSTRATIONS}

(Continued)

Map 4: Location of Community Services, West Warwick

Page 37a

Exhibit 1: Discrepancy Analysis Matrix

Page 38a

Exhibit 2: Number of Programs vs. Risk Factors, Pawtucket

Page 38

Exhibit 3: Number of Programs vs. Risk Factors, West Warwick

Page 40

Table 18: Groups Served by Community

Page 42

Exhibit 4: Groups Being Served, Pawtucket

Page 42

Exhibit 5: Groups Being Served, West Warwick

Page 42

Table 19: Function of Agencies by Community

Page 43

Exhibit 6: Function of Agency, Pawtucket

Page 43

Exhibit 7: Function of Agency, West Warwick

Page 43 


\section{CHAPTER ONE}

INTRODUCTION

The Children, Youth \& Families Issue Group is an organization consisting of faculty members of University of Rhode Islands' Cooperative Extension Service. Since 1990 the group has provided educational outreach programs, technical assistance, evaluation, and planning to community-based social service agencies located in several at-risk Rhode Island communities. One of the many goals of the "Issue Group" is to continuously improve the quality of the programming which they provide. To this end, the group seeks to implement a community-collaborative evaluation program in order to enhance client empowerment and program sustainability. The Children, Youth \& Families Issue Group is in need of research that will produce a cohesive community-based evaluation outreach model. A participatory-normative or value based model could incorporate community values, assets, and goals in order to expand the groups' efforts in Rhode Island.

The purpose of this research project is to develop such a model for the "Issue Group" based on the Development-in-Context Evaluation (DICE) model, designed by Richard M. Lerner. The model has been used to address the following question; How can community-based programs hecome more effective and sustainable; and what can the Children, Youth \& Families Issue Group do to facilitate the process?

The research conducted during this study is presented in five chapters. This introductory chapter provides background and methodological material pertinent to 
the remainder of the document. Chapter two consists of a demographic analysis of Pawtucket and West Warwick, Rhode Island. These two communities represent a high-risk (Pawtucket) and a moderate-risk (West Warwick) community as defined by Cooperative Extension research and will be used as the subject communities for this project. The third chapter provides a detailed overview of the theoretical framework under which the final recommendations presented are based, this is the theory of developmental contextualism. Chapter four provides a sampling of the social service providers located in the communities of Pawtucket and West Warwick. The chapter also presents the findings of a survey conducted with this sample of community-based agencies. The final chapter consists of recommendations designed to enhance the effectiveness and sustainability of community-based programs in Pawtucket and West Warwick through Cooperative Extension programming. These recommendations are to (1) enhance client participation in community-based programs, (2) promote the integration of social services, (3) engage in participatory-normative program evaluation, and (4) integrate the knowledge provided by Cooperative Extension into community programs.

\section{Significance of the problem}

Risk factors are individual or environmental hazards that increase a person or family's vulnerability to negative outcomes (Bogenshneider et al,1992). Risk factors associated with children and families include, but are not limited to, drug and alcohol abuse, negative peer pressure, sexually transmitted diseases, teen pregnancy and parenting, limited resources, school drop-out, lack of family support, crime, 
delinquency, and violence. In November, 1990, the University of Rhode Island College of Resource Developments' Urban Field Center submitted the Secondary Needs Assessment For At-Risk Youth in Rhode Island, to the University of Rhode Islands' Cooperative Extension Service. This document cited risk factor patterns for the 39 cities and towns of Rhode Island and ranked the communities according to the presence of at-risk characteristics. The communities of Central Falls, Woonsocket, Pawtucket, Providence, West Warwick, Newport, and East Providence, were the top seven ranked at-risk communities according to the report. The research was structured under what was found to be the three major areas of concern for these communities, poverty, negative peer pressure, and lack of family support. The at-risk populations identified were found to share a combination of the following characteristics:

- low income, often single parent, female-headed households

- minority, particularly black and Hispanic

- having limited English proficiency

- being a member of a family which fails to instill a strong sense of values and self worth or to provide positive reinforcement for its children

- residing in neighborhoods where a relatively small proportion of the resident majority population send their children to public schools

- being members of families and school districts with low aggregate levels of educational attainment and high rates of school drop-out 
The programmatic mission of the University of Rhode Island Cooperative Extension Children, Youth and Families Issue Group is to provide the following assistance to these, and other, at-risk communities.

- Provide current, research based information, technical assistance and educational programming for children, youth, and families and groups focused on the development of human potential, family well-being and leadership development skills.

- Address youth and family issues by initiating educational outreach programs and networking, to foster cooperation, partnerships, and coalitions.

- Research, create, nurture, support and evaluate children, youth and family development and building human capital programs of the URI Cooperative Extension with the goal of improving the life and environment of at risk children, youth and families including,

-School age child care and after school education

-Coalitions which support community programming for high risk youth

-Development of literacy and technological literacy in youth at risk

-Parent education and parenting skills to support family life

- Develop skills and competencies to assist children, youth and families in becoming self-sufficient and productive citizens.

In order to enhance the effectiveness of the "Issue Group" in meeting their goals the work of applied developmental scientists such as Dr, Lerner has been 
reflected upon. Fostering colearning and community empowerment through the promotion of an ecologically-based program design the following results can be generated.

- The creation of cohesive educational community based outreach program policies that promote the use of participatory and normative (value-based) evaluations of programs at the community level.

- The design of a theoretical model for replication to additional outreach community based program development in Rhode Island Communities.

- Future policy development guidelines for RI Youth \& Families that include; collaborative relationships, programs effective in promoting positive youth and family development, increases community participation and diversity, and long term program sustainability through community empowerment.

These positive outcomes could not only improve the effectiveness of Cooperative Extensions' outreach assistance but may also improve the lives of many children, youth, and family members in Rhode Island's most at-risk communities.

\section{Literature Review}

Several social scientists have addressed the need for an ecological or contextual approach to the problems associated with at-risk children and families. This report will be based primarily on the work of three researchers in this field, Richard M. Lerner, Urie Bronfenbrenner, and the team of Karen Bogenscheider, Stephen Small and David Riley. 


\section{Richard M. Lerner:}

Richard Lerner has been at the forefront of asset based developmental evaluation for over ten years. Asset based program building focuses on the capacities of the residents, institutions, agencies, and programs in the community, rather than what is absent. This positive viewpoint helps to remove the stigma of needy and deficient communities. In America's Youth in Crisis: challenges and options for programs and policies, (1995), Lerner lays out the framework of the Development-InContext Evaluation (DICE) model. The DICE model considers the child as an interactive participant in his/her development, rather than viewing the child simply as a result of external influences. This is what is meant by development-in-context. More importantly, the DICE model promotes positive individual and social development through the incorporation of participatory evaluation into program design and implementation. The design of a DICE model pays attention to the perspectives of the stakeholders in regards to the programs and possible solutions to the issues they are experiencing. It is a colearning model where the stakeholder's are involved with the choice of the evaluation model and are active collaborators in the project. The model focuses on community context, i.e.; the institutions and agencies involved must be educated by the stakeholders as to what development in their particular community context means;

- Who's voices must be included in the program and evaluation

- What are the most salient issues in the minds of the stakeholders

- What specific evaluation tools are appropriate for the community 
The goal of a DICE model is to work collaboratively with the relevant stakeholders to identify and describe the problem, articulate program goals, and identify the questions the community wants answered. The involvement of the community in all stages of program development adds a new asset to the community which can result in sustained community change;

- The stakeholders ability to make better informed decisions about their community is enhanced.

- The ability of the stakeholders and local agencies to develop/implement programs will be enhanced.

- The program itself, collectively implemented, is an added asset to the community.

The DICE model features a colearning approach, where the community eventually takes control of their own outcomes. The DICE model also focuses on the relationships that exist between children and the social system they exist in, that is; family members, schools, peers, neighbors, etc. It should be noted, however, that programs can not be designed as one shot "inoculations" to protect and guide the development of children within their systems. Programs must be long term, life-span orientated, convoys of social support, designed to reinforce and further the positive elements of youth programs (Lerner, 1995). Programs designed in this way must factor in the changing nature of children during the study time frame. According to Lerner, the goal of any DICE based program should be for the members of the 
community to eventually take control of the implementation and evaluation functions, formerly conducted by outside researchers. The essence of a truly effective and contextual program is the reownership and empowerment of a community.

Urie Bronfenbrenner:

The Ecology of Human Development: Experiments by Nature and Design (1979), by developmental psychologist Urie Bronfenbrenner, includes a conceptual framework for analyzing the layers of the environment that have a formative influence on the development of a child. The framework is applied to a variety of settings in which children commonly develop. Bronfenbrenners' perspective emphasizes not only the importance of the child's interaction with adults and other children but also the influences on the child of the larger environment.

The State of Americans: this generation and the next (1996), also by Urie Bronfenbrenner, examines the relationships among social and economic factors and trends which affect families and children; changing attitudes and values, crime, the economy, family structure, poverty, education, and population aging.

Karen Bogenschneider, Stephen Small and David Riley:

"An Ecological, Risk-Focused Approach to Addressing Youth at Risk Issues", was written by Karen Bogenschneider, Stephen Small and David Riley and published in The Teen Assessment Project Dissemination Manual (1992). The article outlined a model in which the follow four basic principals were held; 
1. Positive child and youth development can be promoted by reducing risks and promoting protective factors in a young persons environment.

2. The most effective interventions attempt to influence risk and protective factors at multiple levels including family, peers, school, work, neighborhood, and community.

3. Community assessment will make it possible for interventions to focus on actual risks as opposed to assumed risks.

4. The more risks a young person faces, the more likely he or she is to experience negative developmental outcomes such as underachievement, school drop-out, substance abuse, and teen pregnancy.

The risk-focused ecological model suggests that comprehensive, community-based efforts are needed to prevent the problems young people face. The most effective prevention programs will assess risk factors and protective factors at each level of the child's ecology and then target programs to the gaps that exist. (Bogenschneider et al;' 1992).

\section{Methods and Procedures}

The first step in the research process was to become familiar with research previously conducted on the subject of participatory normative evaluation models. Materials cited in the literature review section of this proposal, as well as other related work were reviewed. Relevant Cooperative Extension materials were also be collected and integrated into the research. The next step was to collect and analyze the relevant demographics for the communities of Pawtucket, and West Warwick, Rhode Island. As stated in the report; $\underline{\text { Secondary Needs Assessment For At-Risk }}$ Youth in Rhode Island, these communities represent a high (Pawtucket) and a 
moderate level (West Warwick) at-risk community. The following general population demographics were analyzed:

- Population by race

- Age distribution

- Educational attainment

- Household income

- Family income

- Race of householder

Because the focus of this research is on children, youth, and families the following demographics specific to children were also be collected and analyzed:

- Children in poverty

- Living arrangements of children

- Teenage pregnancy and parenting

- High school graduation rates

- Income assistance (AFDC and Food Stamp recipients)

A vital part of this evaluation was the sample of local community social service agencies and programs. This sampling included any organizations available to the community for counseling, child care, job training, shelter, etc. These resources have been incorporated into the recommendations resulting from this reassert. A survey designed to collect information which secondary data alone could not provide was applied to the sampled agencies in Pawtucket, and West Warwick. The 
community agencies sampled in West Warwick include, Joyful Noise Daycare, Kent County YMCA, and the Kent County VNA. Pawtucket sites included, the Barton Street Community Center, Blackstone Valley C.A.P., Community Counseling Center, Family Service Society, Halfway House-PACC, Projecto Esparanza, Providence Head Start, and the Cunningham Elementary School Child Opportunity Zone (COZ).

The information from the community surveys was used to conduct a discrepancy analysis designed specifically around the risk factors identified during the research. The analysis compared the risk factors believed to exist locally to the service providers in the communities. The potential "gap" between risk factors and the programming offered by the community agencies was therefore illustrated for each community. The analysis also identified areas of duplication in service provision. Once this analysis was complete final recommendations were presented. The work of Lerner, Bronenbrenner, and Bogenshneider, were reflected upon in order to suggest holistic community strategies for countering risk behaviors while enhancing the effectiveness of community-based programming. These findings are presented in the iifth and innal chapter of this report. 


\section{CHAPTER TWO \\ DEMOGRAPHICS}

\section{Introduction}

Demographic data for each locality must be collected and analyzed before an assessment of community services can begin. This is done so that a clear picture of the two communities can be drawn and a basis for further data collection can be established. "Children grow up, not in isolation, but in ever-widening environments Children are influenced first and foremost by their families but also by their peers. their school and work settings, and the community in which they live. Development has no single cause; rather multiple factors working together shape development" (Bogenschneider et al). Therefore, data on many different areas in the lives of the children and families of Pawtucket and West Warwick has been compiled. The acknowledgment of the interrelations within children's development is at the heart of the ecological approach. That is, each area of developing childrens lives affect the other areas of their lives, and the lives of others around them.

This chapter consists of three major sections. The first section contains general demographic information for the communities of Pawtucket and West Warwick, Rhode Island. Information regarding population, family income, educational attainment, etc., will be presented side by side for comparison. The second section contains demographic data specific to the children of Pawtucket and West Warwick. These data are compared to state-wide child demographics so that the degree of difference or similarity between the two communities can be judged. The final section 
consists of general conclusions that can be drawn from the information presented in the previous sections.

General Demographics

Pawtucket is a city of 72,644 persons located at the strategic falls of the Blackstone River and the upper tidewaters of the Narragansett Bay (Map 1). Between the founding of Pawtucket in 1671 , and the present, the city has grown to be a highly developed manufacturing center. The population count for the city during the 1990 Census was 72,644 . This represents a $2.0 \%$ change ( 1,440 persons) from the 1980 population of 71,204 . Table 1 illustrates this change as it pertains to the different categories of race

Table 1 .

POPULATION BY RACE: PAWTUCKET, R.I

\begin{tabular}{lcccc}
\hline RACE: & 1980 & 1990 & Change & $\% 1990$ Pop. \\
\hline White & 67,841 & 64.836 & -3005 & 89.3 \\
Black & 993 & 2608 & 1615 & 3.6 \\
Indian & 97 & 203 & 106 & 0.3 \\
Asian & 176 & 472 & 296 & 0.6 \\
Hispanic & 2502 & 5211 & 2709 & 7.2 \\
Other & 2097 & 4525 & 2428 & 6.2 \\
\hline TOTAL: & 71204 & 72644 & 1440 & 100 \\
Source: U.S. Census of Population and Housing, 1990. &
\end{tabular}

as defined by the U.S.Census of Population and Housing. (Note: Hispanic origin is not considered a race, but has been added into these demographics). Measuring the change in demographics over time is important in recognizing the trends in population change in the community. It is important to provide services for ethnic groups who may be new to the area and require special assistance such as english language instruction. 


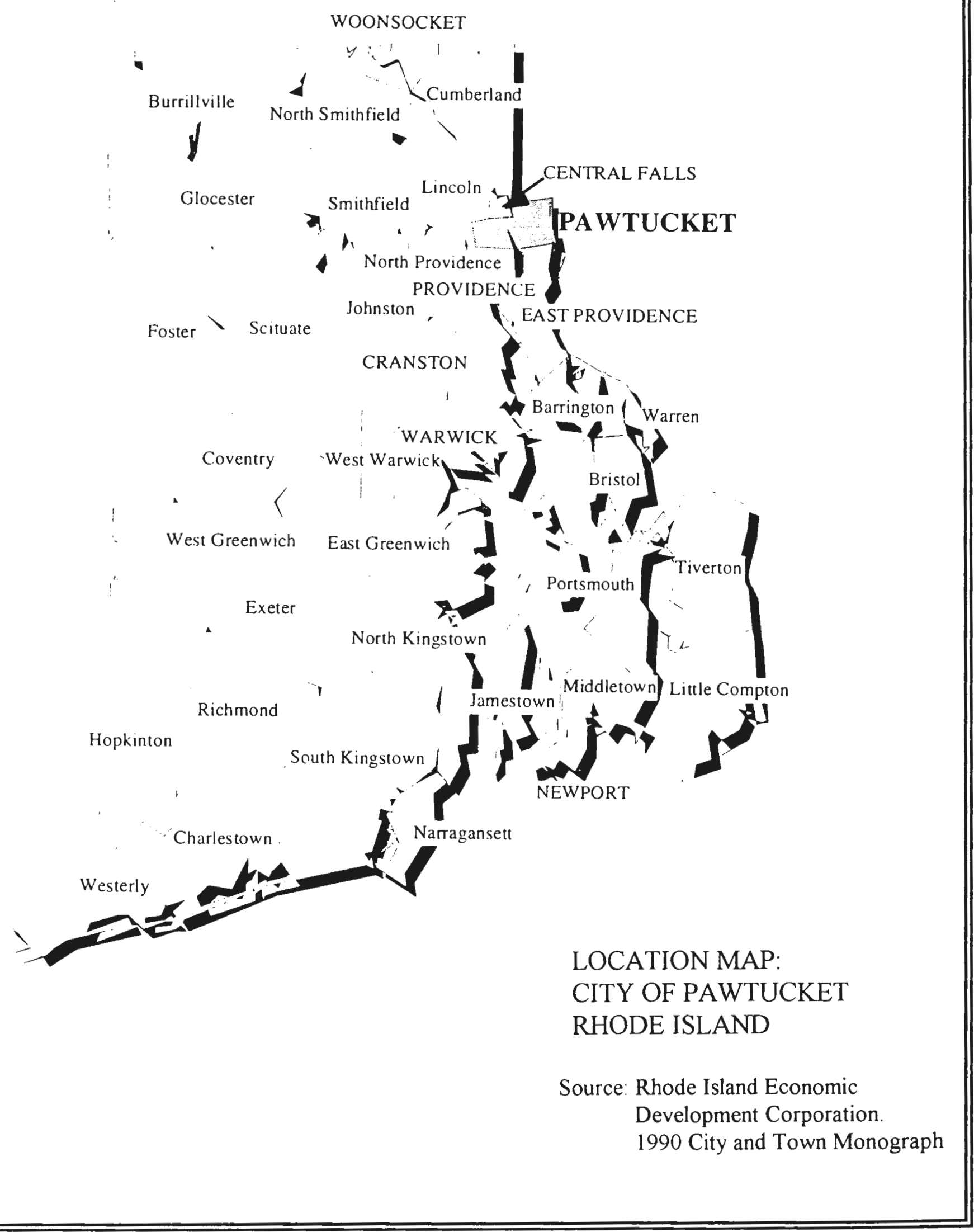


West Warwick is a town of 29,268 persons located to the southwest of Providence, bordering Coventry, Cranston, and Warwick (Map 2). Like Pawtucket, the town was a highly developed manufacturing center during the industrial revolution Since the early 1900's the industrial growth of area has leveled off. Beginning after World War II, decentralization of manufacturing and Suburbanization changed the character of West Warwick. In many ways West Warwick has the growth pattern of a suburb, and the social problems of a city. The population count for the town as of the 1990 Census was 29,268 . This represents a $8.3 \%$ change ( 2,242 persons) from the 1980 population of 27,026 . Table 2 illustrates this change as it pertains to the different categories of race as defined by the Census. The data indicate that the town is predominately populated by Caucasians $(97.6 \%)$.

Table 2.

POPULATION BY RACE: WEST WARWICK, R.I.

\begin{tabular}{lcccc}
\hline \hline RACE: & 1980 & 1990 & Change & \%1990 Pop. \\
\hline White & 26.717 & 28.579 & 1862 & 97.6 \\
Black & 97 & 235 & 138 & 0.8 \\
Indian & 17 & 53 & 36 & 0.2 \\
Asian & 128 & 281 & 153 & 1.0 \\
Hispanic & 330 & 120 & 212 & 0.4 \\
Other & 67 & 542 & 53 & 1.9 \\
\hline TOTAL: & 27026 & 29268 & 2454 & 100
\end{tabular}

Source: U.S. Census of Population and Housing. 199().

Table 3 displays a comparative age breakdown for the populations of Pawtucket and West Warwick. In 1990, 23\% of the population of Pawtucket and $22.4 \%$ of the population of West Warwick were under 18 years old The age distribution of the population is useful in determining the percentage of children who may be at risk in the community. 


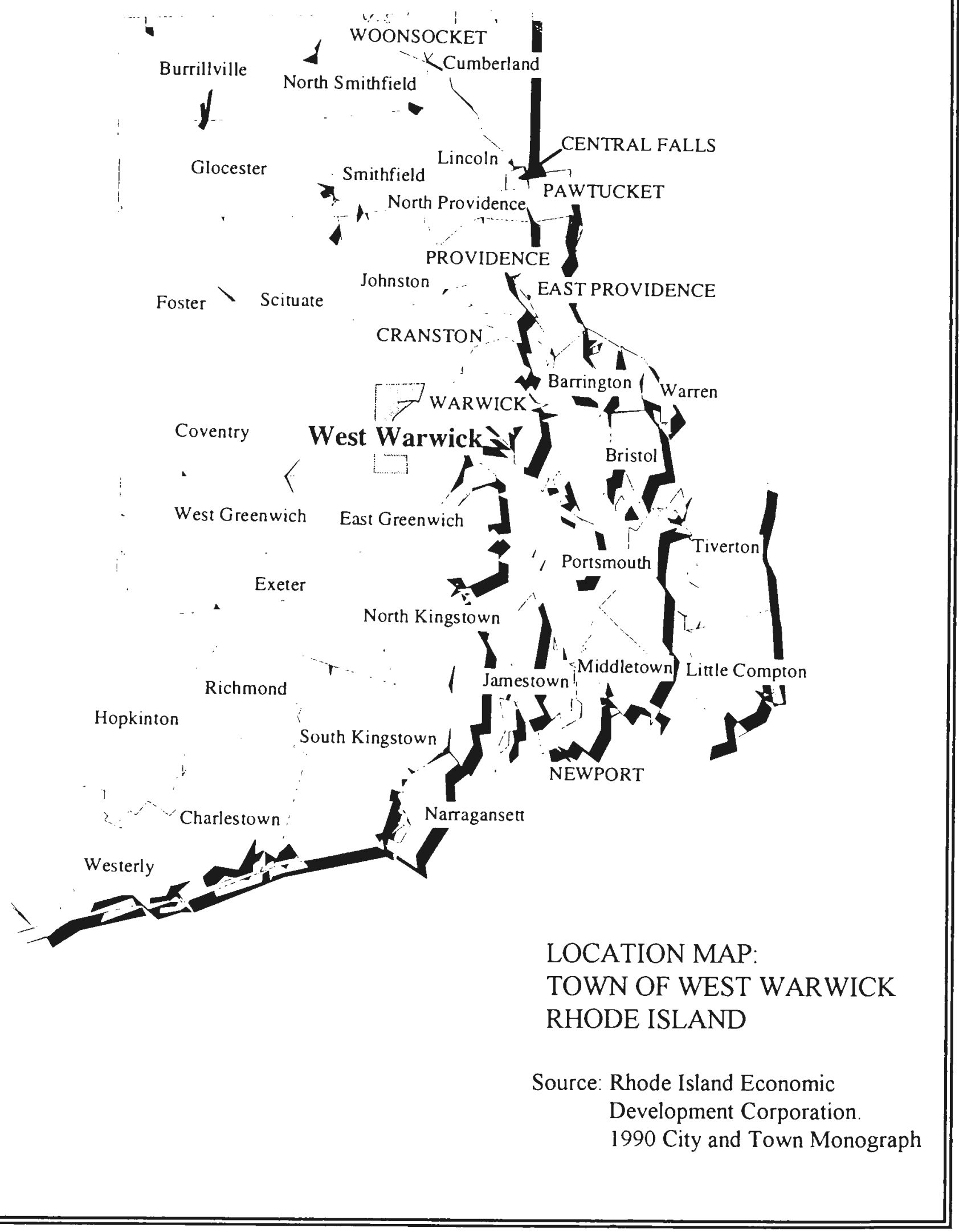


Table 3.

AGE DISTRIBUTION: PAWTUCKET \& W. WARWICK.

\begin{tabular}{ccccc}
\hline \hline & \multicolumn{2}{c}{ PAWTUCKET } & \multicolumn{2}{c}{ W. WARWICK } \\
Age & Persons & \% of Pop. & Persons & \% of Pop. \\
\hline Under 5 & 5384 & 7.4 & 2024 & 6.9 \\
5 to 17 & 11335 & 15.6 & 4536 & 15.5 \\
18 to 20 & 2936 & 4.0 & 1258 & 4.3 \\
21 to 24 & 4595 & 6.3 & 1962 & 6.7 \\
25 to 44 & 23499 & 32.3 & 10153 & 34.7 \\
45 to 54 & 6403 & 8.8 & 2662 & 9.1 \\
55 to 59 & 3112 & 4.3 & 1178 & 4 \\
60 to 64 & 3526 & 4.9 & 1394 & 4.8 \\
65 to 74 & 6732 & 9.3 & 2573 & 8.8 \\
75 to 84 & 3904 & 5.4 & 1203 & 4.1 \\
Over 85 & 1218 & 1.7 & 325 & 1.1 \\
\hline TOTAL: & 72644 & 100 & 29268 & 100 \\
Source: U.S. Census of Population and Housing, 1990. &
\end{tabular}

The age cohort size of families and parents whom may require social services can be determined through age distribution analysis. Specific data regarding children at risk has been included in the second section of this chapter.

Educational attainment is another important factor to consider when analyzing the demographics of the communities. Pawtucket is a community where in $61.6 \%$ of the population have a high school diploma or higher, and $13.1 \%$ have a bachelor's degree or higher. Table 4 illustrates the educational attainment of those persons over the age of 25 in both communities. In West Warwick $70.3 \%$ of the population have a high school diploma or higher, and 14.8\% have a bachelor's degree or higher. Table 4 also indicates that $29.7 \%$ of the persons over 25 years old in West Warwick, and $38.4 \%$ of those in Pawtucket, have not received a High School diploma, or an equivalent thereof. 
Table 4.

EDUCATION-PERSONS OVER 25, 1990

\begin{tabular}{lcccc}
\hline \hline & \multicolumn{2}{c}{ PAWTUCKET } & \multicolumn{2}{c}{ W. WARWICK } \\
Attainment Level: & Persons & \% of Total & Persons & \% of Total \\
\hline Less than 9th Grade & 8058 & 16.6 & 2183 & 11.2 \\
9th-12th, No Diploma & 10593 & 21.8 & 3608 & 18.5 \\
High School Graduate & 14684 & 30.2 & 6464 & 33.2 \\
Some College & 6324 & 13.0 & 2940 & 15.1 \\
Associates Degree & 2595 & 5.3 & 1406 & 7.2 \\
Bachelor's Degree & 4357 & 9.0 & 2129 & 10.9 \\
Graduate/Professional & 1993 & 4.1 & 768 & 3.9 \\
\hline TOTAL OVER 25: & 48604 & 100 & 19498 & 100 \\
Source: U.S. Census of Population and Housing, 1990. & &
\end{tabular}

Educational attainment levels may significantly impact the household and family

income levels earned by the population; the median household income in Pawtucket

was $\$ 26,541$ per year in 1990 .

Table 5.

HOUSEHOLD INCOME: PAWTUCKET \& W. WARWICK, 1990

\begin{tabular}{lcccc}
\hline & \multicolumn{2}{c}{ PAWTUCKET } & \multicolumn{2}{c}{ W. WARWICK } \\
Income Bracket: & \# of HH's & $\%$ of Total & \# of HH's & $\%$ of Total \\
\hline Less than $\$ 5000$ & 1363 & 4.6 & 489 & 4.2 \\
\$5000 to $\$ 9999$ & 3712 & 12.5 & 1271 & 10.9 \\
\$10000 to \$14999 & 3145 & 10.6 & 846 & 7.2 \\
\$15000 to \$24999 & 5707 & 19.3 & 1964 & 16.8 \\
\$25000 to \$34999 & 5000 & 16.9 & 1867 & 15.9 \\
\$35000 to \$49999 & 5924 & 20.0 & 2377 & 20.3 \\
\$50000 to \$74999 & 3448 & 11.7 & 2085 & 17.8 \\
\$75000 to \$99999 & 812 & 2.7 & 550 & 4.7 \\
\$100000 to \$149999 & 329 & 1.1 & 181 & 1.5 \\
Over \$150000 & 149 & 0.5 & 77 & 0.7 \\
\hline TOTAL HOUSEHOLDS: & 29596 & & 11707 & 100
\end{tabular}

Source: U.S. Census of Population and Housing 1990.

Of the 29,596 households in Pawtucket, 27.7\% have a household income under the poverty line for a family of four of $\$ 15,150$ per year. The median household income in 
West Warwick is $\$ 31,625$ per year. Of the 11,707 households in the town, $22.3 \%$ have a household income under the poverty level for a family of four.

A slightly different statistic is family income, the median family income for Pawtucket, 1990 , was $\$ 33,679$ the same statistic for West Warwick in 1990 , was $\$ 39,351$. Table 6. displays the family income distributions for both communities in 1990.

Table 6.

FAMILY INCOME: PAWTUCKET \& W. WARWICK, 1990.

\begin{tabular}{lcccc}
\hline \hline & \multicolumn{2}{c}{ PAWTUCKET } & \multicolumn{2}{c}{ W. WARWICK } \\
Income Bracket: & \# of Family & $\%$ of Total & \# of Family & $\%$ of Total \\
\hline Less than $\$ 5000$ & 400 & 2.1 & 178 & 2.3 \\
$\$ 5000$ to $\$ 9999$ & 1172 & 6.1 & 423 & 5.5 \\
$\$ 10000$ to $\$ 14999$ & 1585 & 8.3 & 379 & 4.9 \\
$\$ 15000$ to $\$ 24999$ & 3362 & 17.5 & 1017 & 13.1 \\
$\$ 25000$ to $\$ 34999$ & 3437 & 17.9 & 1214 & 15.7 \\
$\$ 35000$ to $\$ 49999$ & 5046 & 26.3 & 1983 & 25.6 \\
$\$ 50000$ to $\$ 74999$ & 3041 & 15.9 & 1794 & 23.2 \\
$\$ 75000$ to $\$ 99999$ & 737 & 3.8 & 541 & 7 \\
\$100000 to $\$ 149999$ & 285 & 1.5 & 149 & 1.9 \\
Over \$150000 & 103 & 0.5 & 62 & 0.8 \\
\hline TOTAL FAMILIES: & 19168 & 100 & 7740 & 100 \\
Source: U.S. Census of Population and Housing 1990. & &
\end{tabular}

In comparison to household income, only $16.5 \%$ of the families in Pawtucket have incomes under the poverty line. In Pawtucket families with a median income less than $\$ 20,300$ per year, are considered to be of very low income according to HUD standards. Low income families are those which earn $\$ 29,301$ to $\$ 32,480$ per year. Moderate income families are those which earn $\$ 32,481$ to $\$ 46,690$ per year.

The last demographic displayed in this section refers to the racial dynamics of the households in Pawtucket and West Warwick. Table 7 illustrates that $91.5 \%$ of the households in Pawtucket, and $98.3 \%$ of the households in West Warwick, are headed 
by a white householder. Hispanic headed households are the second largest in

Pawtucket at 5.6\%. Hispanic headed households are the second largest group in West

Warwick as well at $1.3 \%$.

Table 7.

RACE OF HOUSEHOLDER: PAWTUCKET \& W. WARWICK

\begin{tabular}{lcccc}
\hline & \multicolumn{2}{c}{ PAWTUCKET } & \multicolumn{2}{c}{ W. WARWICK } \\
Race & \# of HHr's & $\%$ of Total & \# of HHr's & $\%$ of Total \\
\hline White & 27199 & 86.7 & 11517 & 98.3 \\
Black & 924 & 2.9 & 86 & 0.7 \\
Indian & 84 & 0.3 & 16 & 0.1 \\
Asian & 135 & 0.4 & 72 & 0.6 \\
Hispanic & 1651 & 5.3 & 151 & 1.3 \\
Other & 1369 & 4.4 & 31 & 0.3 \\
\hline Total: & 31362 & 100 & 11873 & 100 \\
Source: U.s. Census of Population and Housing 1990. & &
\end{tabular}

Section III. Demographics of Children.

Due to the nature of the programming provided by the Children, Youth \& Families Issue Group, demographics specific to children must be analyzed. The Census defines children as all persons under the age of 18 . Table 8 contains the number and percentage of children, and minority children, to the total population of the two communities and the state as a whole. There were 16,719 children in Pawtucket, and 6,560 children in West Warwick at the time of the 1990 Census enumeration. The percentage of children in the state who are minority's is $12.2 \%$.

Pawtucket has a higher percentage of minority children than the state at $16.2 \%$, while West Warwick has a much lower percentage of $3.4 \%$.

Table 8.

CHILD POPULATION, 1990

\begin{tabular}{lcccc}
\hline \hline Locality & Total Pop. & \# Children & \% Children & \% Minority Children \\
\hline Pawtucket & 72644 & 16719 & 23.0 & 16.2 \\
W. Warw. & 29268 & 6560 & 22.4 & 3.4 \\
State & 1003464 & 225690 & 22.5 & 12.2 \\
\hline Source: 1996 Rhode Island KiDS COUNT Factbook
\end{tabular}


Children at risk of not achieving their full potential are often children in poverty. The social, physical, and economic environment that children grow up in plays a significant role in shaping their development. "Children who grow up in poverty are more likely to go without necessary food and clothing, live in substandard housing, be victims of crime and violence, lack basic health care, and have unequal access to educational opportunities. Poor children are more likely to be born low birth-weight, die in infancy or childhood, have health problems that affect school performance, become a teen parent, or drop out of school" (1996 Rhode Island KIDS COUNT Factbook, p. 14). Table 9 displays the number of children living in poverty in each community, as well as the number of children under the age of six in the city who are living in poverty.

Table 9.

CHILDREN IN POVERTY, 1990

\begin{tabular}{|c|c|c|c|c|}
\hline Locality & \# of Child. & $\%$ of Child. & \# Chd. $<6$ & $\%$ Chd. $<6$ \\
\hline Pawtucket & 2525 & 15.5 & 1096 & 17.3 \\
\hline W. Warw. & 746 & 11.8 & 291 & 13.0 \\
\hline State & 30022 & 13.5 & 12912 & 16.3 \\
\hline
\end{tabular}

Another important factor associated with children at risk are the living arrangements of their households. "Children in single parent families are at increased risk of living in poverty when compared to children in two-parent families" (1996 Rhode Island KIDS COUNT Factbook, p.8). Table 10 displays living arrangement data for the children of Pawtucket.

Table 10.

LIVING ARRANGEMENTS OF CHILDREN IN FAMILIES, 1990

\begin{tabular}{lcrcrc}
\hline \hline Locality: & \# Children & 2 Parent & \% 2 Parent & 1 Parent & \% I Parent \\
\hline Pawtucket & 15242 & 11266 & 73.9 & 3976 & 26.1
\end{tabular}




\begin{tabular}{lccccc} 
W. Warw. & 6097 & 4711 & 77.3 & 1386 & 22.7 \\
State & $2111+2$ & 164666 & 78.0 & +6476 & 22.0 \\
\hline Source: 1996 Rhode Island KIDS COOTT Fatbook
\end{tabular}

According to the data, $73.9 \%$ of the children of Pawtucket live in two parent families, where as $26.1 \%$ live in single parent families In West Warwick, $71.8 \%$ of the children of the town live in two parent families, and $21.1 \%$ live in single parent families. (This accounts for $93 \%$ of the child population, the other $7 \%$ are not living in either single, or duel parent families.)

Teenage pregnancy is another major risk factor that needs to be evaluated The hirths to teens statistics are compiled by calculating the number of births to females between the ages of 15 to 17 per 1000 females. Pre-teen childbearing threatens the development of both the teen parents and their children. Teen mothers are often less likely to obtain adequate prenatal care and are less likely to have the financial and social support needed to raise healthy children. "Being a teen parent seriously limits subsequent education and employment prospects. Nationally, three out of five teen mothers drop out of school. Their life earnings are less than half of those who wait until age twenty before bearing their first child" (1996 Rhode Island KIDS COUNT Factbook, p.32).

\section{Table 11 .}

BIRTHS TO TEENAGE MOTHERS. 1988-92

\begin{tabular}{lcrr}
\hline \hline Locality & \# Girls & \# Births & \multicolumn{2}{c}{ Birthrate } \\
\hline Pawtucket & 1286 & 265 & 41.2 \\
W. Warw: & 480 & 63 & 26.2 \\
State & 17279 & 2574 & 29.8 \\
\hline Source: 1996 Rhode Island KIDS COUNT Factbook
\end{tabular}


In Pawtucket there were 265 births to teen mothers between 1988 and 1992, a rate of 41.2 births per 1000 teenage girls, almost double the state-wide rate. In comparison, West Warwick's birth-to-teen rate was 26.2, which was less than the state-wide rate (see Table 11).

Receiving a High School diploma may be one of the most vital factors in the development of a child. Children who receive a quality education are more likely to grow into capable, self-sufficient adults who contribute to their communities" (1996 Rhode Island KIDS COUNT Factbook, p.64). Such persons are less likely to rely on public assistance later on in life. The High School Graduation Rate is a useful way to compare communities in this regard. The graduation rate is the percentage of the ninth-grade class that is expected to graduate, based on the existing drop-out incidence among 9th, 10th, 11 th, and 12th grade students. Table 12 displays the High School Graduation Rate as calculated for the city of Pawtucket, West Warwick. The table shows the number of students enrolled, the percent with limited English proficiency (L.E.P.), and the graduation rate, for the two communities and the state.

Tabie 12 .

HIGH SCHOOL GRADUATION RATE. 1994

\begin{tabular}{lccc}
\hline \hline Locality & \# Enrolled & \% L.E.P. & Grad Rate \\
\hline Pawtucket & 9101 & 11.4 & 61.8 \\
W. Warw. & 4028 & 3.6 & 78.1 \\
State & 144931 & 5.6 & 81.8 \\
\hline Source: 1996 Rhode Island KIDS COUNT Facbook
\end{tabular}

These data show that Pawtucket has a much higher percentage students with L.E.P. than West Warwick, and a graduation rate 20 percentage points lower than that of the state. 
One factor that may influence the graduation rate for these communities is the number of children enrolled in the Head Start program. "Head Start is a comprehensive early-childhood development program for low-income preschool children (primarily ages three to five) and their families. Head Start program components include education, parent involvement, social services, health and nutrition, and mental health services. These services help low-income children acquire the readiness skills they need in order to enter the public school system on an "equal Footing" with more economically advantaged children" (1996 Rhode Island KIDS COUNT Factbook, p.60). Table 13 indicates the percentage of eligible children

Table 13.

CHILDREN ENROLLED IN HEADSTART, 1995

\begin{tabular}{lccc}
\hline \hline Locality & \# Eligible & \# Enrolled & \% Enrolled \\
\hline Pawtucket & 671 & 80 & 12.0 \\
W. Warw. & 154 & 99 & 64.0 \\
State & 6192 & 2379 & 38.0 \\
\hline Source: 1996 Rhode Island KIDS COUNT Facbook
\end{tabular}

enrolled in Head Start in Pawtucket, West Warwick, and the state. Unfortunately, only $12 \%$ eligible for the program in Pawtucket are enrolled. The result of these educational deficiencies can be a high percentage of jobless teens. Table 14 displays data regarding the amount of 16 to 19 year old teens who were not in school and not working as of 1990 .

Table 14.

16-19 YEAR OLD'S NOT IN SCHOOL AND NOT WORKING. 1990

\begin{tabular}{lcccc}
\hline Locality & $\# 16-19$ & Non-Graduates & Graduates & \% Jobless \\
\hline Pawtucket & 3632 & 81 & 303 & 10.6 \\
W. Warw. & 1478 & 46 & 89 & 9.1 \\
State & 59290 & 1484 & 3339 & 8.1 \\
\hline Sourco: 1996 & Rhode Island KIDS CoUNT Fadbook & &
\end{tabular}


In order to ease the economic burden of families in poverty several programs have been made available to families in these communities. In 1990, 2,282 families in Pawtucket, and 535 families in West Warwick were receiving Aid To Families with

Table 15.

CHILDREN RECEIVING PUBLIC ASSISTANCE, 1995

\begin{tabular}{|c|c|c|c|c|c|}
\hline \multirow[b]{2}{*}{ Locality: } & \multicolumn{2}{|c|}{ AFDC \& F-Stamps } & \multirow{2}{*}{$\begin{array}{c}\text { F-Stamps } \\
\text { Only }\end{array}$} & \multirow{2}{*}{$\begin{array}{l}\text { All with } \\
\text { Either }\end{array}$} & \multirow{2}{*}{$\begin{array}{l}\text { Percent of } \\
\text { Children }\end{array}$} \\
\hline & Families & Children & & & \\
\hline Pawtucket & 2282 & 4403 & 895 & 5298 & 28.5 \\
\hline W. Warw. & 535 & 989 & 243 & 1232 & 17.1 \\
\hline State & 20458 & 40789 & 7950 & 48739 & 20.2 \\
\hline
\end{tabular}

Dependent Children (AFDC), and Food Stamps. In Pawtucket 28.5 percent of children under 18 years old were receiving some sort of public assistance. The average monthly AFDC benefit for a Rhode Island family of three is $\$ 554$ per month. The average monthly Food Stamp benefit for the same size family in Rhode Island is $\$ 268$. The combined benefits of these programs for a three person family in this state is $\$ 822$ per month. "Income support programs such as AFDC and Food Stamps have a significant impact on the ability of poor families to provide food, shelter, and clothing for their children. While AFDC and Food Stamp benefits do not prevent a family from falling below the poverty line, they provide a minimal subsistence for poor families" (1996 Rhode Island KIDS COUNT Factbook, p. 18).

The supplemental food program known as WIC (Women, Infants, and Children) is another source of assistance for the children and families of these communities. The program serves pregnant, postpartum, and breast feeding women, as well as women with children under the age of five. "the General Accounting Office has estimated that for every dollar spent in the WIC program, $\$ 3.30$ is saved in federal, 
state, and local government program benefits for the new child's first eighteen years" (Schneider 1995, p.56). Table 16 displays the participation data for the WIC program in the subject Communities. Both Pawtucket and West Warwick have higher participation percentages than the state as a whole.

Table 16.

WOMEN, INFANTS RECEIVING W.I.C., 1995

\begin{tabular}{lccc}
\hline Locality & \# Eligible & \# Participating & \% Participating \\
\hline Pawtucket & 3198 & 2749 & 86.0 \\
W. Warw. & 777 & 613 & 79.0 \\
State & 32886 & 23016 & 70.0 \\
\hline Source: 1996 Rhode Island KIDS COUNT Factbook
\end{tabular}

Yet another form of nutritional assistance is the National School Breakfast Program.

Table 17.

CHILDREN RECEIVING SCHOOL BREAKFAST, 1995

\begin{tabular}{lccccc}
\hline \hline Locality & \# Low Inc. & \% Breakfast & \# Schools & \# w/ Bfast & \# with out \\
\hline Pawtucket & 5030 & 21.0 & 18 & 2 & 16 \\
W. War. & 1066 & 29.0 & 7 & 1 & 8 \\
State & 45689 & 63.0 & 309 & 116 & 193 \\
\hline Source: I996 Rhode Island KIDS COUNT Factbook & & &
\end{tabular}

The program provides free or reduced price breakfast and lunch to children who live in households which earn below $185 \%$ of the federal poverty level. "Children who participate in the Scincol Bı eakfast Program have better school attendance, are more likely to arrive to school on time, and have higher standardized test scores than nonparticipants" (1996 Rhode Island KIDS COUNT Factbook, p.36). Table 17 displays the participation statistics for this program in the study area. The table includes the number of children eligible for the benefit, the percent who participate, the number of schools which offer the assistance, and the number which do not. Sadly, of the 309 public school in the state only 116 participate in this program, leaving 16,905 eligible 
low-income children without this assistance. In Pawtucket only two of the eighteen public schools participate. Similarly, only one of the seven West Warwick public schools offer the School Breakfast Program.

\section{Section IV. Chapter Conclusion:}

Both Pawtucket and West Warwick are in need of social services, this fact had been established long before the inception of this project. Analysis of these demographics has confirmed this belief and illuminated some differences between the two communities. Pawtucket seems to be a community with greater risk factors to contend with than West Warwick. Although both communities have significant risk factors present, the problems of Pawtucket are in many cases more severe. For example, the Pawtucket has a higher percentage of minorities in the population (11\%) than West Warwick (7\%) and the state as a whole (8.5\%). Consequently, Pawtucket also has the highest percentage of minority children of the three populations. Minorities make-up $16 \%$ of Pawtucket's child population ( $4 \%$ higher than the state), where as West Warwick has a minority child population percentage of only $3.4 \%$. This is significant because maity risk behaviors have been found to be more pronounced among minority populations (Lerner, 1995). Pawtucket also has a greater percentage of families living below the poverty line then West Warwick and the state. Six percent of the families in the state and $13 \%$ of the families in West Warwick are living below the poverty line. In Pawtucket $17 \%$ of all families are living below the poverty line of $\$ 15,150$ per year for a family of four. The living arrangements of children in Pwtucket are more condusive to risk behavior than those of West Warwick and the state as a 
whole. In Pawtucket $26 \%$ of children live in single-parent families. In West Warwick, as well as the rest of the state approximately $22 \%$ of children live in single-parent families. Pawtucket is at greater risk for teen pregnancy as well. The state birth-rate to teenage girls ages 15 to 17 is 29.8 per/1000. West Warwick has a rate lower than that of 26.2 per/1000. Pawtucket has a much higher rate than both localities at 41.2 births for every 1000 girls between 15 and 17 years old. High school graduations rates in Pawtucket have improved between the years of 1993 and 1994, growing up $2 \%$. However, for those same years the city's graduation rate was $61.8 \%$, which was $16 \%$ lower than West Warwick's rate of $78 \%$ and $20 \%$ lower than the state graduation rate of $81.8 \%$.

These data indicate a need for social services in both communities. Although West Warwick seems to be less at-risk than Pawtucket the community is still one of the states ten most at-risk localities. The next chapter outlines the theoretical framework on which the recommendations of this study are based; this is the theory of developmental contextualism. Subsequent chapters outline the services available to the children anu families of Pawtucket and West Warwick and identify areas that can potentially be strenthened based on this theory. 


\section{CHAPTER THREE \\ DEVELOPMENTAL CONTEXTUALISM}

\section{Introduction}

The theory of developmental contextualism as presented by Dr. Richard Lerner, illustrates a vision of integrative, reciprocal, and dynamic relations among developing individuals, families, and contexts. The theory, when implemented as part of the DICE model, synthesizes research with program design, delivery, and evaluation. The model involves both multiprofessional collaboration and full partnership with the communities within which the research and service are being conducted. The people whom the research is intended to serve are full collaborators in the process of research and outreach. (Lerner, 1995). This chapter outlines the concept of developmental contextualism and presents the key elements of the DICE model.

Developmental Contextualism

Developmental contextualism stresses that bi-directional relations exist among the multiple levels of organization involved in human life, e.g., biology, psychology, social groups, and culture (Bronfenbrenner, 1977). The changes that occur in these relations over time constitute the behavior and development of individuals.

Developmental contextualism views these relationships as dynamically interactive, i.e., they are reciprocally influential over the course of human development. Within this perspective, the context for development is not seen as merely as a simple stimulus environment, but rather as an ecological environment (Lerner, 1995). Therefore, children have come to be understood as active producers of their own development. 
"These contributions primarily occur through the reciprocal relations individuals have with other significant people in their contexts: for example, children with family members, caregivers, teachers, and peers" (Lerner 1995, p.17) Parents and their children have significant reciprocal effects on each others development. Children stimulate different reactions in their parents, and these reaction provide the basis of feedback to the children (Schneirla, 1957). However, these relationships do not exist in isolation, both the child and the parent have other social roles which influence their development and in turn influence the development of one another. "The sorts of relationships in these other social networks in which children and parent engage when outside of their roles of child or parent, respectively, can be expected to influence the parent-child relationship" (Bronfenbrenner, 1977) The core idea in developmental contextualism is that the individual and his or her context can not be separated, both are fused together throughout the lifespan. Research designed to address the issues faced by children, youth, and families must recognize the complexity of these relationships in order to be effective. Failure to do so may result in inadequate research and application. "That is, research inattentive to the complexity of perșoncontext relations will be deficient in that either it will fail to appreciate the substantive nature of individual, familial, or relationship variation, and/or it will mistakenly construe variation around some (potentially significant inapplicable) mean level as, at best, error variance, that is, differences that are at random and nonmeaningful" (Lerner 1995, p. 32). This situation may result in programming which is insufficient to meet the needs of the persons it has been designed to serve. 


\section{Implications for Programming}

Fostering the attributes of positive youth development can not be successfully done by a single person, family, or institution. All segments of the community must collaborate in the raising of America's youth (Lerner, 1995). The changing characteristics of the American family, (i.e., divorce, working parents) lend further support to this theory. Families need support from other sectors of their communities to both promote positive development of youth, and to prevent the actualization of risk factors facing today's families. Community based programs can make several potential contributions to positive youth development. According to the Carnegie Corporation of New York (1992) these contributions can include;

- Providing opportunities for youth to engage in positive social relationships with peers and adults.

- Teaching youth important life skills such as goals setting, teamwork, problem solving, and communication.

- Offering youth opportunities to make contributions to their communities.

- Providing youth with a sense of being part of a positive group experience.

- Facilitating a sense of self-competence among youth.

Unfortunatley, many community based programs are underfunded, under staffed, have low staff morale, and lack specific training. Furthermore, many of their services are aimed at only one of the interrelated set of problems confronting youth, rather than the co-occurance of problems and risk behaviors (Carnegie Corp., 1992). 
Several researchers have reviewed the results of evaluations of youth programs aimed at addressing the risk factors facing America's youth, these researchers include Dryfoos (1990), Schorr (1988), Little (1993), and Hamburg (1992). Each of the researchers have indicated the following social institutions as being vital to adolescent development and successful prevention programs: family, peer groups, workplace, and school. Other components of successful programs include programming which is sensitive to the individual needs of the clientele. This requires non-bureaucratic, userfriendly service provision (Schorr, 1988). This focus on individual attention coincides with a key element of development in contextualism which is active client participation. Furthermore, focus on the individual allows a programs to have a preventive orientation. "Through a focus on the individual and his or her distinctive needs, a program may be able to strengthen and empower the person for long-term, healthy development" (Little, 1993).

In the vein of developmental contextualism, Dryfoos (1990), and Hamburg (1992) have indicated that programs should not promote the separate focus on mental health, public health, social service, and educational issues. "Rather, programs and policies should promote an integrated, case management approach to services" (Dryfoos, 1990). Little (1993) supports this assertion and adds that the vast majority of youth-serving programs reach only very small numbers of youth. However, programs which grow in scale (i.e., number of youth served) do so through integrative partnering (Little, 1993). 
In order to address these issues in the application and evaluation of programs a participatory-normative approach could be taken. A value-based, normative approach to evaluation which engages the community, and especially the youth and family program participants in the design, implementation, and analysis of the evaluation, empowers the community and enhances the efficacy of the program (Weiss and Greene, 1992). According to Weiss and Greene (1992) a participatory and normative approach to evaluation;

- Builds on the values and meaning system of the youth, families, and other stakeholder groups in the community

- Engages this community coalition as active participants (partners) in the evaluation

- Enhances the capacity of the community partners to themselves identify, organize, and use their assets to conduct planned actions to attain goals they value.

This participatory-normative approach to evaluation serves to counteract the often uninformed, and disempowering nature characteristic of many evaluations of youth and family serving programs (Lerner, 1995). The approach enfranchises community stakeholders as full partners in programming decisions. "Simply, a participatorynormative approach to evaluation is a value-added component to an intervention that, through the collaborative conduct of the evaluation, the capacity of the community stakeholders to better direct their own future development in enhanced" (Lerner 1995, p.83).

The Development-in-Contextualism Evaluation (DICE) Model 
The DICE Model builds on the idea of promoting social development and change through the use of a participatory-normative evaluation. The model is based upon the following maxims;

- Think holistically or contextually, make no distinctions between the program and the context in which it occurs

- Include as many voices or stakeholders as possible, especially those from different points of the life-span

- Focus on the actions involved in forming effective programs

- Realize that reality is complex and socially constructed

- Build evaluation into the day to day function of every program.

To implement these ideas programs must be built from the "inside out", that is to focus on solutions within the community. Rather than focusing on the needs and deficiencies of a community, programs should begin with a clear commitment to discovering a communities capacities and assets (Lerner, 1995). Programs which focus on their clients problems and the value of the "service" provided for them can cause people to view themseives as people with special needs dependent on outside assistance. "Young people can begin to see themselves as fundamentally deficient, victims incapable of taking charge of their own lives or their communities future" (Kretzmann \& McKnight 1993, p.4). Focusing on needs or deficits also leads to other problems such as; fragmentation, funding going to service providers not to the community, undermining of local leadership, creating a maintenance and survival strategy and thwarting community development (Lerner, 1995). By focusing on the capacities, 
skills, and assets of children, parents and other community stakeholders solutions to problems can come from the inside out. Asset based programs start with what is in the community, the capacities of the residents and of the programs and other institutions in the area, not what is absent. Programs should be based on the perspective, values, and problem-solving capacities of the local agencies and residents. A strong and positive relationship between local residents, associations, institutions, and agencies must be established so that a collaborate, caring community can be created. (Lerner, 1995).

The design of DICE model evaluation must consider the perspectives of the stakeholders as to the proper techniques to be used, this is a process of colearning. This colearning serves to educate the researcher as to what development in their particular community context means. The researcher must find out from the community; (1) who are the people who's voices must be included as part of the program and its evaluation, (2) the issues that the community wants to have addressed and that are seen as most salient, (3) what specific evaluation tools are necessary and appropriate to deploy in the community. (Lerner, 1995). Through the participation of the stakeholders in this process their capacity to make better informed decisions about their community can be enhanced.

The next chapter presents data from surveys and interviews conducted with a sample of service providers in Pawtucket and West Warwick. The final recommendation presented in Chapter 5 are an attempt to apply the theory of developmental contextualism to the context of these communities. 


\section{CHAPTER FOUR \\ COMMUNITY SERVICES}

\section{Introduction}

Families and children experiencing risk factors may require support and assistance from the community at various stages of their lives. Communities rich in support programs are better equipped to deal with the challenges which their residents may face. The information presented in this chapter is based on a sample of social services available to the children and families of Pawtucket and West Warwick, Rhode Island. The sampling of service providers was based in part on a directory of services prepared by Cooperative Extensions' Individuals, Youth and Families Issue Group in 1992. A discrepancy analysis was conducted based on the information regarding the function and clientele of the agencies sampled. Data was also gathered through personal and telephone interviews with the service providers themselves.

\section{Community Service Providers: Pawtucket}

\section{Blackstone Valley Community Action Program}

This non-profit, community based agency provides social and health services for community residents and senior citizens, including counseling and work experience. Spanish, Portuguese, and French is spoken. The programs are available to clientele from the Pawtucket area, no fees are charged.

Street Address:

129 School Street

Pawtucket, RI. 02860

401-723-4520

\section{Community Counseling Center}

This community center provides counseling for substance abuse, sexual and physical abuse, and for ACOA (Adult Children of Alcoholics). The agency provides crises intervention facilities, outreach programs for children to prevent abuse and neglect. The agency also provides alternative educational programs for behaviorally and 
emotionally disordered children. Blue Cross, Welfare, and other private insurance is accepted. Sliding fee's are available for the uninsured.

Street Address:

160 Beechwood Avenue

Pawtucket, RI. 02860

401-722-5573

\section{Barton Street Community Center}

The center provides accommodations for needy individuals up to a period of three months. It provides a comprehensive social service program, counseling facilities, referrals, and literacy programs. There are no fees asked.

Street Address

183 Barton Street

Pawtucket, RI 02860

401-723-4140

\section{Family Service Society of Pawtucket and Vicinity}

The Society offers individual, marital, and family counseling. Access to in-patient services are available, as well as accredited clinical internships in social work and counseling. The agency also provides a drug and alcohol programs. Workshops in crisis intervention, family enrichment, and stress management. Services are $\$ 25$ for the first session, a sliding fee scale based on personal income is used thereafter.

Street Address:

33 Summer Street

Pawtucket, RI. 02860

401-723-2124

\section{Pawtucket Alcohol Counseling Center}

This agency provides outpatient counseling for substance abusers and their families, daily group therapy, educational programs, ACOA programs, and driving while intoxicated counseling. Some insurance policies accepted, sliding fee scales are available for the uninsured.

Street Address:

104 Broad Street

Pawtucket, RI. 02860

401-726-8080

\section{Projecto Esperanza}

Projecto Esparanza offers after school programs, youth and family counseling, and case management to Hispanic clientele. No fees are charged for these services.

Street Address:

765 Dexter Street

Central Falls, RI. 02863

401-723-9676 


\section{Providence Head Start}

This agency provides needs assessment, outreach, social services, and counseling for children and their parents. Emphasize is placed on parent participation. No fees are charged.

Street Address:

20 Almy Street

Providence, RI. 02909

401-272-1760

\section{Child Opportunity Zone-Cunningham/Slater Schools}

The COZ focuses on early childhood education, parent involvement in education, after school/drop-out prevention, 4-H programs, traffic and safety classes, adult literacy training, skills workshops, etc.

Street Address:

Cunningham Elementary School

40 Baldwin Street

Pawtucket, RI. 02860

401-729-6293

Map 3 displays the geographical location of the services sampled in Pawtucket as part of this research. The map indicates a concentration of social services in the center of the city.

Community Service Providers: West Warwick

Joyful Noise Daycare

Joyful Noise provides childcare for low to moderate income families in the Warwick and West Warwick area.

Street Address:

9 New London Avenue

West Warwick, RI 02893

\section{Kent County Mental Health}

The majority of the mental health services available to the people of West Warwick comes from this multi-faceted agency. Kent County Mental Health offers a variety of counseling programs including drug and alcohol programming, sexually transmitted disease treatment and counseling, and basic health services. The agency also runs childcare programs in the community such as the Elm and Echo valley housing project childcare programs.

Kent County Visiting Nurses Association (VNA) 


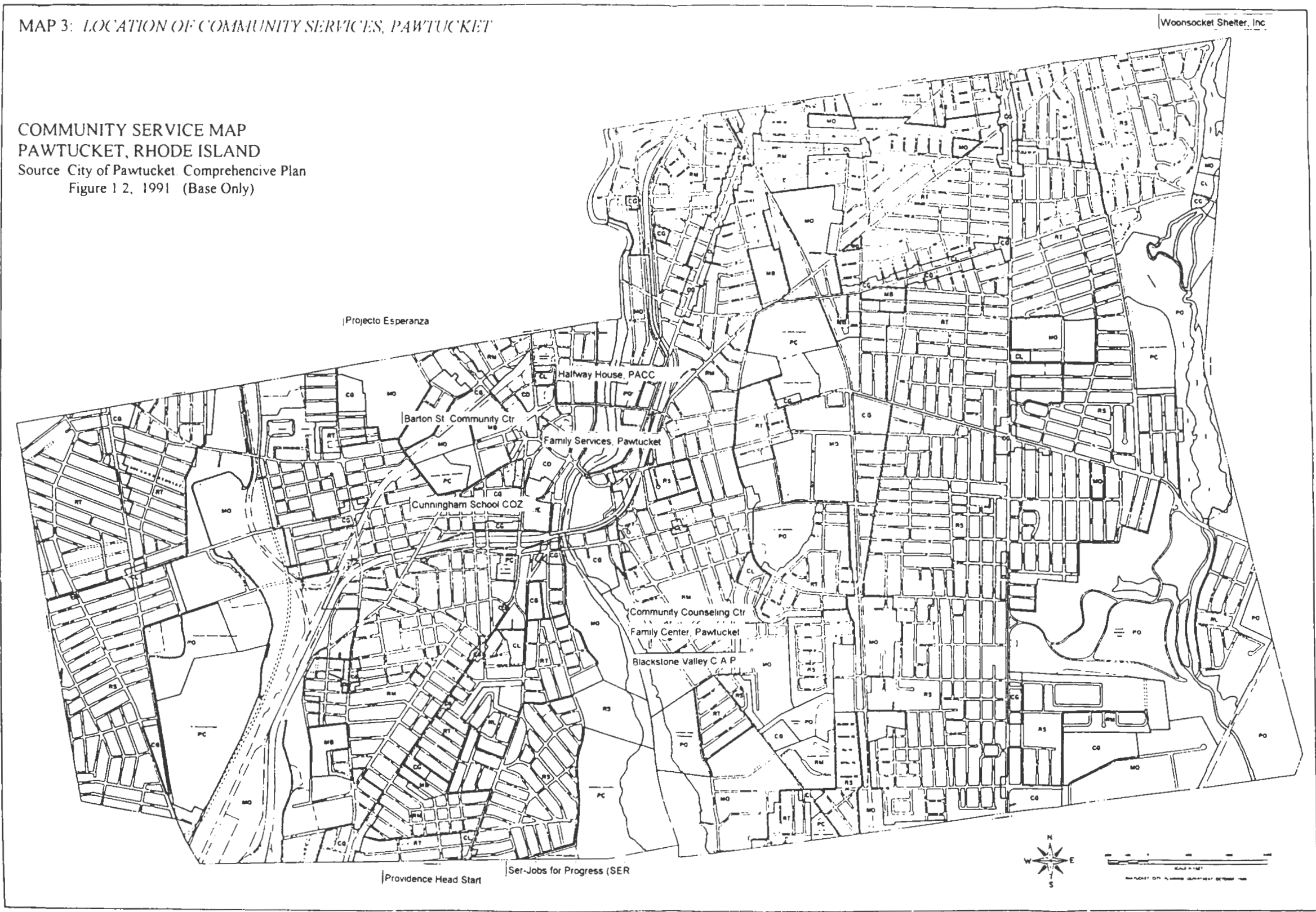


The VNA provides nursing, rehabilitation services, physical therapy, and consultation services. Maternal-child health programs targeting young families who are at risk, hospice programs are also available. Fees are covered by insurance.

Street Address

51 Health Avenue

Warwick, R.I. 02886

401-737-6050

\section{Kent County YMCA}

The YMCA offers affordable childcare, athletics, recreation, and preschool opportunities to low-moderate income families in Kent County.

Street Address:

900 Centerville Road

Warwick, RI 02886-4372

401-828-0130

\section{Chace House/ Elizabeth Buffum}

Chace House provides temporary shelter, education, and support, for women and children who have difficult decisions to make regarding domestic violence.

Counseling, outreach, and substance abuse programs are also available.

Street Address:

P.O. Box 9476

Warwick, R.I. 02889

401-738-1700

\section{Channel One}

This program offers education and skill workshops to community residents as well as conducting day trips and retreats.

Street Address:

Warwick City Hall Annex

Warwick, R.I. 02886

401-739-5230

\section{Directions}

Individual, group, and family drug counseling, psychological evaluation and testing, educational, vocational, and legal assistance, outreach and referral programs are conducted through this non-profit agency.

Street Address:

1071 Main Street

West Warwick, R.I. 02893

401-828-6373 


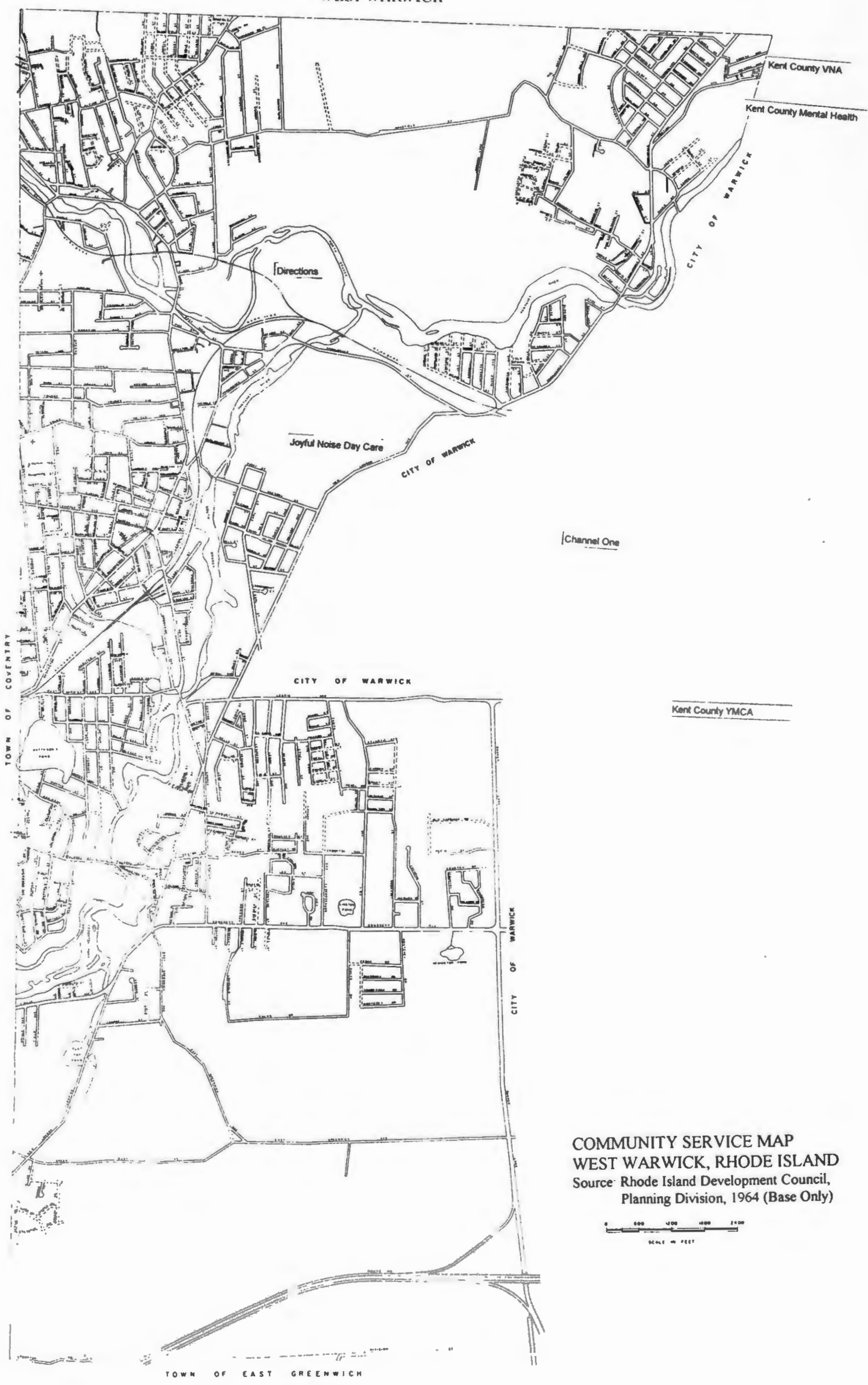


Map 4 displays the geographical location of the services sampled in West Warwick.. The map illustrates a dispersed pattern of social services, the majority being located in Warwick, not West Warwick.

\section{Discrepancy Analysis}

In order to gain a comprehensive understanding of the various services provided to the people of Pawtucket and West Warwick information regarding the sampled agencies was used to conduct a discrepancy analysis. The information for this analysis is presented in the matrix labeled Exhibit 1. The matrix is used to compare the risk factors believed to be present in the communities with the protective factors offered by the various agencies and programs. By organizing the data in this way gaps and/or duplication in social service provision can be easily identified.

Exhibit 2 displays the results of the analysis for the City of Pawtucket, Rhode Island. The number of agencies or programs that address each risk factor have been totaled

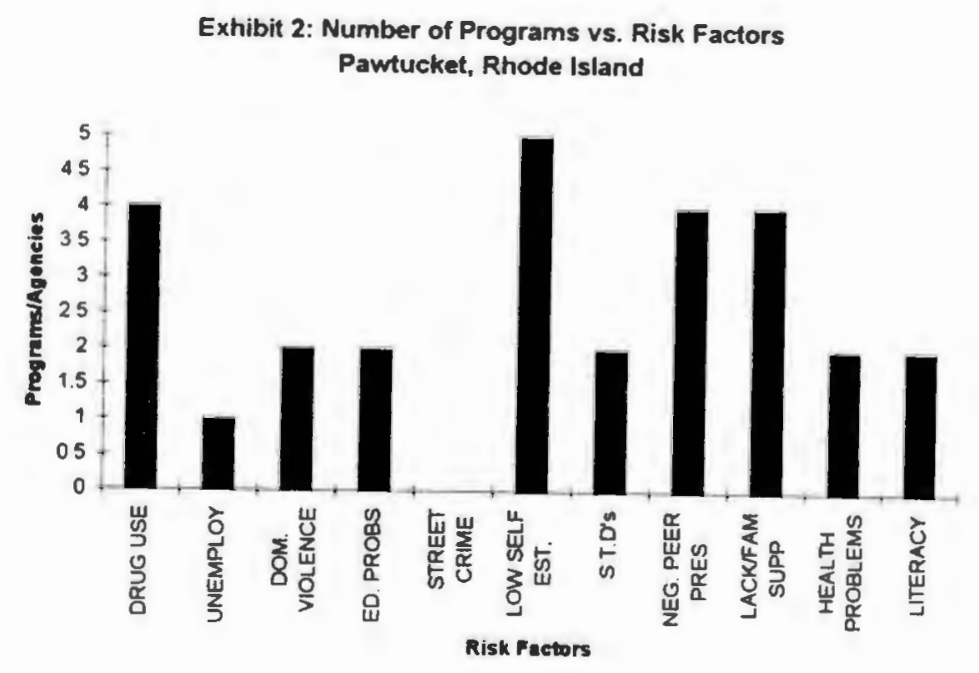


Exhibit 1: Discrepency Analysis Matrix

SOCIAL SERVICES AVAILABLE VERSUS RISK FACTORS - PAWTUCKET, RHODE ISLAND:

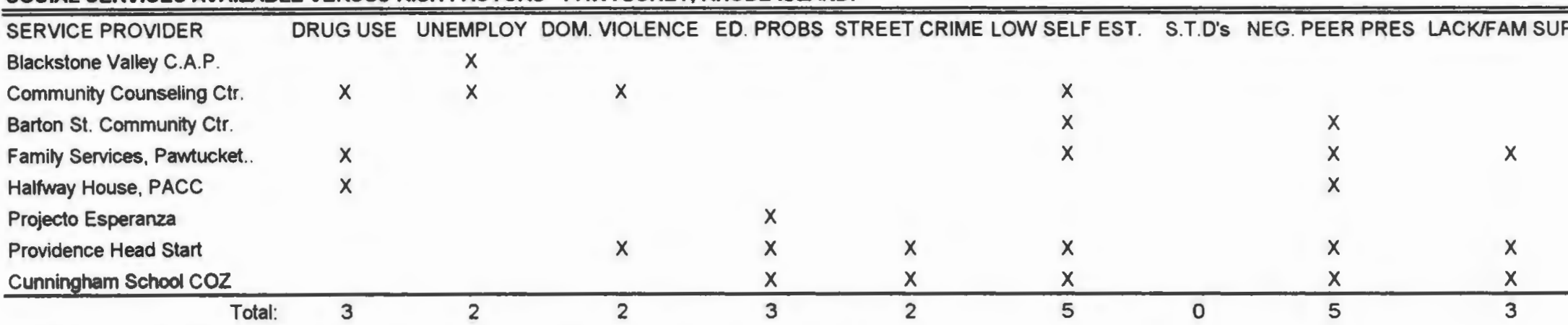

Source: Coperative Extension: Individuals, Youth and Families Issue Group, Directory of Services, 1992

SOCIAL SERVICES AVAILABLE VERSUS RISK FACTORS - WEST WARWICK, RHODE ISLAND:

\begin{tabular}{|c|c|c|c|c|c|c|c|c|}
\hline SERVICE PROVIDER & DRUG USE & UNEMPLOY & DOM. VIOLENCE & ED. PROBS & STREET CRIME LOW SELF EST. & S.T.D's & NEG. PEER PRES & LACKFAM SUF \\
\hline Joyful Noise Day Care & & & & & $x$ & & $x$ & $x$ \\
\hline Kent County Mental Health & $x$ & & & & & $x$ & & $x$ \\
\hline Kent County VNA & $x$ & & $x$ & & $x$ & $x$ & & $x$ \\
\hline Kent County YMCA & & & & & $x$ & & $x$ & \\
\hline Horgan Elementary School & & & & $x$ & $x$ & & $x$ & \\
\hline Chace House/Eliz. Buffum & $x$ & & $x$ & & $x$ & & $x$ & $x$ \\
\hline Channel One & & $x$ & & $x$ & & & & \\
\hline Directions & $x$ & & & & & & & \\
\hline & 4 & 1 & 2 & 2 & 5 & 2 & 4 & 4 \\
\hline
\end{tabular}

Source: Coperative Extension: Individuals, Youth and Families Issue Group. Directory of Services, 1992 
The subjective nature of these data must be stressed before analyzing this graph. Risk factors such as low self esteem and negative peer pressure are often indirectly addressed by various programs. In other words, an agency's goal may not be to increase self esteem but that may occur as an outcome of their actions. Therefore, many programs/agencies included in the data have been given credit for addressing risk factors that they may not have explicitly attempted to counter-act. This situation may be responsible for the fact that most number of agencies address low self esteem according to the data. A large number of agencies also address drug abuse, negative peer pressure, and lack of family support. It should be emphasized that these are often overlapping risk factors (as are many risk factors). Health problems are the focus of half of the agencies and programs sampled in Pawtucket. The category of risk factors labeled health problems includes mental and behavioral problems, medical ailments, and substance addiction treatment. There are also many programs and agencies in Pawtucket that address literacy and educational problems, which are often one and the same problem. The growing Hispanic population of Pawtucket (see Chapter Two) warrants the provision of these services, almost half the agencies studied offer some sort of literacy assistance. Domestic violence and unemployment are addressed equally by the agencies considered in Pawtucket. Four of the ten agencies had programs for either victims of domestic violence, or unemployed persons. There are two risk factors that do not appear to be directly controlled for according to the data, these are sexually transmitted diseases (S.T.D.'s) and street crime. Although many of the agencies offer some form of health services, none of the ten studied directly treat 
sexually transmitted diseases. Only two of the ten agencies or programs address street crime directly. This only means that there mission statement or stated goals do not include these items, they may indirectly control for these risk factors.

Like Pawtucket, the sample data show that majority of the services available to the people of West Warwick address the problems of low self esteem, negative peer pressure, and lack of family support. The subjective nature of these categories partially explains the dominance of these risk factors in community services. However, programs geared toward the problems of children at-risk often address these vital areas.

Exhibit 3 graphically displays the data for West Warwick regarding the number of social services provided for each risk factor considered. Drug and alcohol abuse problems are also heavily programmed by the agencies in West Warwick

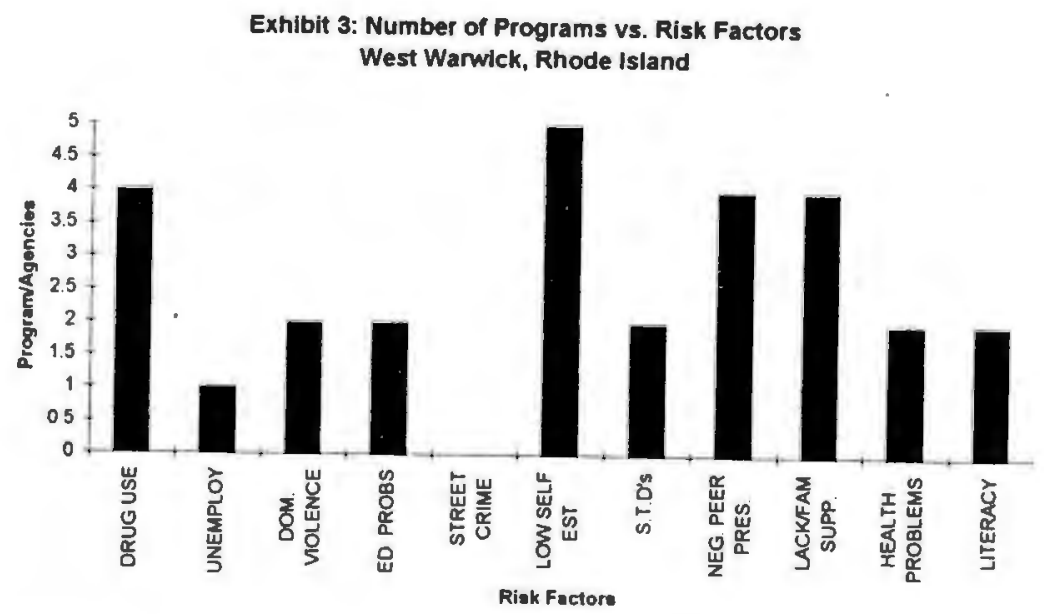

Domestic violence, health problems, literacy and education problems were all equally programmed by the agencies surveyed. As in the case of Pawtucket, street crime was not directly addressed. Unlike in Pawtucket however, sexually transmitted 
diseased are the focus of a number of social service providers accessible to children, youth, and families in West Warwick. This is largely due to the presence of Kent County Mental Health, and the Kent County Visiting Nurses Association (VNA) in the Warwick area. The Warwick area did not have an abundance of services available dealing with unemployment, only the Channel One program appeared to directly provide employment assistance. While giving testimony in front of the United States senate in 1986, Urie Bronfenbrenner stated that the most powerful destroyer of family life, with the most serious consequences, is the unemployment of the breadwinner. This statement may indicate that unemployment counseling and skills training could be enhanced in these communities in order to further assist at-risk families

\section{Survey Findings}

The following data are the results of telephone interviews conducted with the service providers sampled in Pawtucket and West Warwick. Qualitative data gathered during the survey process has illuminated facts that would not have been identified through the use of the community asset matrix alone. The surveys were designed to gather several different pieces of data ranging from descriptive to quantitative in nature. This information was useful in reinforcing the data gathered for the previous sections.

The nature of the opening questions regarded the name, location, and function of the service provider, as well as which groups they were attempting to serve. In many of these cases this information was already known, however it is often useful to 
hear this information from the agency first hand. Table 18 displays the data regarding which group or groups the agency being surveyed was attempting to serve.

Table 18.

\begin{tabular}{|c|c|c|c|c|c|c|c|c|}
\hline \multicolumn{9}{|c|}{ roups Served by Community } \\
\hline & Parents & Teens & Ment. ill Children & Minorities & Jobless & Homeless & Single Par. & Drop Outs \\
\hline & 4 & 5 & 4 & 7 & 3 & 2 & 4 & 3 \\
\hline Warw. & 4 & 3 & 2 & 5 & 3 & 3 & 3 & 2 \\
\hline
\end{tabular}

Both communities focus much of their social service provision on minorities.

However, West Warwick also has a significant amount of service provision directed toward children. These data have been graphically presented for comparison in Exhibits 4 and 5.
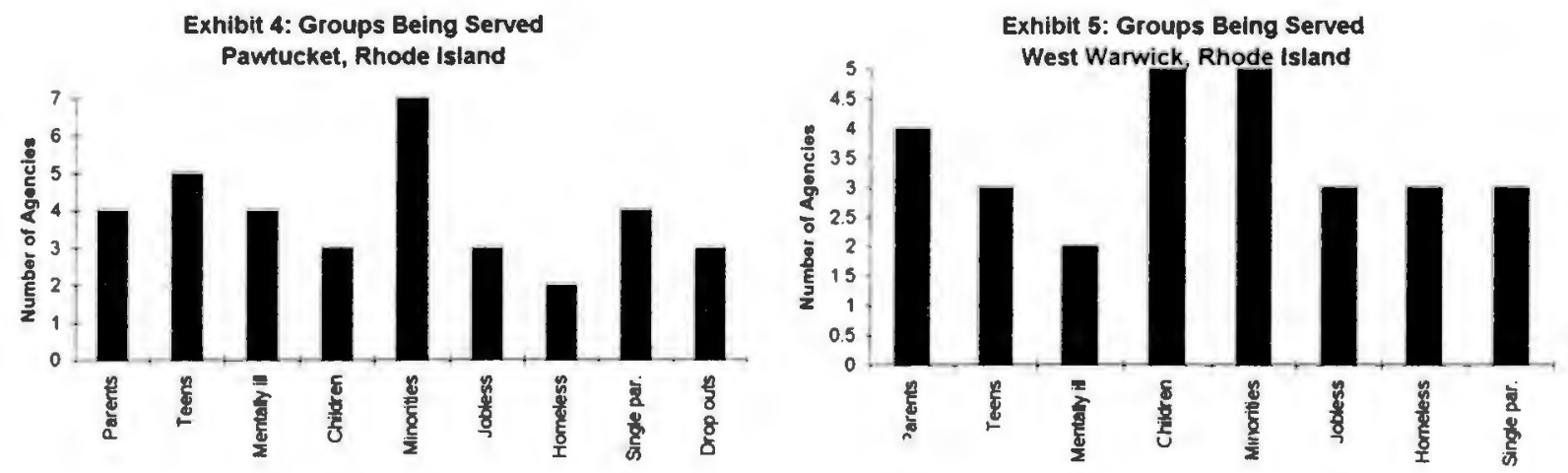

Parents, teenagers, and children were the second most served groups according to the survey. Homeless, jobless, and drop-outs were the three most undeserved groups in both communities.

The function of the agencies sampled have been tabulated in a similar manner. It should be noted that there is some overlap in agency function, i.e., most agencies 
have many functions and they often overlap with other agencies. Table 19 displays the survey results regarding the function of the agencies sampled.

Table 19.

Function of Agencies by Community

Pawtucket
Day Care Education Counsel W. Warw. 1 2 2 5 5 5 4 4 4 1

The three most common functions of the agencies in both communities was counseling, drug and alcohol addiction treatment, and health service provision. In Pawtucket there is also a significant amount of agencies which provide emergency shelter and skills training which are not provided at the same level in West Warwick Exhibits 6 and 7 graphically illustrate the data for Pawtucket and West Warwick
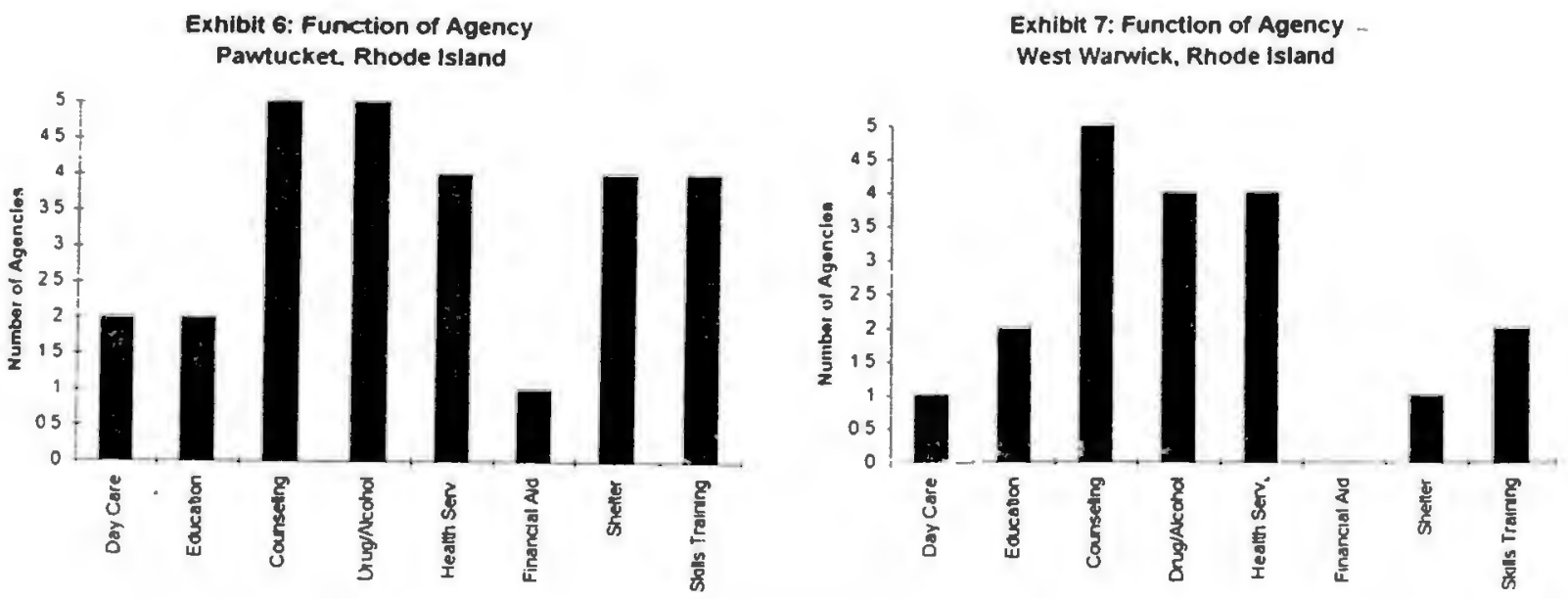

As indicated by Table the most common function in the two communities combined are general counseling, drug/alcohol counseling, and health service provision, respectively.

The respondents were then asked to state their opinions on some organizational strengths and weaknesses of their program or agency. The lack of adequate funding was the most often stated weakness of the agencies surveyed. 
Variations on this theme included, lack of modern facilities, the need to double-up classrooms, minimal staff, etc. Strengths generally included statements regarding their experienced staff or their ability to provide services to a diverse citizenry

The most important questions regarded the presence of a client advisory council or board in their organization. The DICE model on which the final recommendations of this study are based, stresses the need for community input and participation in social service programs. This participation is critical in empowering the people of the community and giving ownership of the programs to the clients This ownership is the key to program sustainability. Therefore, the presence of a client input mechanism was a very important datum to gather on these agencies. Of the thirteen community agencies surveyed only five reported having some form of client advisory board. These agencies were the Community Counseling Center of Pawtucket, Providence Head Start, and Kent County Mental Health, and the Barton Street Community Center, and the Cunningham Elementary School COZ.

Community Counseling Center, Inc., gains input from its clientele through the use of an advisory board. This board consists of five members who are "consumers" of the agencies services. These five members sit on the Board of Directors of the agency where they have direct input into programming decisions. Providence Head Start also has an advisory board from which input can be gained. This board consists of parents (of enrolled children), former students, and agency representatives. The members are involved in the planning and the evaluation of programs as well as the decision making process Kent County Mental Health utilizes three advisory boards 
consisting of consumers and family members. The organization gains important feedback and suggestions from these boards which they use to guide their strategic planning process. The Barton Street Community Center has a Board of Directors which is made up from and elected by the clientele of the center. The Board meets once a month to plan the operations and programs of the community center.

The most common method of gaining clientele feedback for the agencies which did not have such a board was the use of a questionnaire. These are surveys given to the clientele at the time of their treatment. While this is a useful method in gathering data it lacks the influence of programming that an advisory board may command. The next and final chapter of this report will further explore methods of client participation and input as components of the DICE model; as well as suggest other methods for enhancing the effectiveness of social service provision in Pawtucket and West Warwick, Rhode Island. 


\section{CHAPTER FIVE \\ RECOMMENDATIONS}

\section{Introduction}

This chapter synthesizes the information presented thus far into four recommendations designed to enhance the effectiveness and sustainability of community programming in Pawtucket and West Warwick, Rhode Island These recommendations are to ( 1 ) enhance client participation in community-based programs, (2) promote the integration of social services, (3) engage in participatorynormative program evaluation, and (4) integrate the knowledge provided by Cooperative Extension into community programs.

\section{Enhance Client Participation}

Developmental contextualism stresses that diversity and context should be the focus of both research and outreach efforts. To that end intensive, individualized attention should be given to the participants of community based programs (Lerner, 1995). Enhanced client participation may help service providers to realize the specific motivations, interests, aspirations, and needs of their clientele. Furthermore, client involvement in the evaluation and decision making process empowers individuals to take control over programs which are in place in their communities. Such empowerment can serve to enhance the sustainability and the effectiveness of programming. As mentioned in chapter four only four of the thirteen community agencies surveyed utilize some form of client input mechanism. These agencies are as 
follows; Community Counseling Center, Inc., Providence Head Start, Barton Street Community Center, and Kent County Mental Health. It is there for recommended that the remaining community agencies be encouraged to engage their clientele in some form of feedback/input process. The Children, Youth \& Families Issue Group may be able to provide suggestions for various methods possible to gain input from community program participants.

The data analyzed in chapter four also suggests that many of the community programs sampled focus on the remediation and/or treatment of risk behaviors rather than focusing on positive youth development. By taking this approach programs may be acting as little more than "Band-Aids" to problems which have developed at earlier stages of their clients' development. To remedy this situations Little (1993) suggests that programs could shift their efforts to enhancing the following characteristics in their young clientele;

- Competence: Developing practical skills to sustain and improve the quality if their lives such as, literacy, employability, vocational/academic skills...

- Connectıon: Promoting the development of caring human relationships through mentoring, peer tutoring, community service...

- Character: Promoting the values that give meaning and direction to the lives of children and adolescents. E.g., honesty, equity, courage, pride, and hope

- Confidence: Providing experiences that lead to hope and self-esteem . Examples of agencies which focus on these characteristics in Pawtucket and West Warwick are the Cunningham School Child Opportunity Zone (COZ), Channel One, 
and Projecto Esparanza. These programs and agencies develop practical skills and positive values at various stages during the life-cycle of their clientele. These programs are not simply designed to counsel individuals on risk behaviors which has already become problematic. However, it should be stressed that the agencies which do provide such counseling are also extremely important to these communities. They should, in my opinion, be used as a second line of defense against risk behaviors, the first line being early intervention programs.

\section{Promote the Integration of Services}

The separate focus on mental health, social service, drug counseling, educational issues, etc., may detrimental to the effectiveness the various community services. It has been suggested by researchers such as Dryfoos (1990); Hamburg (1992), and Schorr (1988) that an integrated, case management approach to services may be a more effective strategy. The partnering of service providers can solve the problem of one client or family being "served" by several disconnected agencies and programs (Little,1993). This approach may also utilize the already scarce funding for these services more efficiently. Another reason for the integration of services is the interrelatedness of high-risk behaviors. "As noted by Dryfoos (1990), 10\% of all 1017 year-olds in America engage in behaviors associated with all four major categories of high-risk behaviors, i.e., drug and alcohol abuse, unsafe sex, school failure, and delinquency and crime" (Lerner 1995, p78). Therefore, a package of services may be needed within each community experiencing high-risk behavioral problems. 
Kent County Mental Health is an example of an agency surveyed which provides many services throughout the community. The agency is responsible for several health service programs as well as day care programs in the Echo Valley and Elm Street public housing projects. However, these services are not integrated into one program, they are instead fragmented throughout several programs. The matrix (Exhibit 1) presented in chapter four also illustrates the duplication of services in Pawtucket and West Warwick. For example, seven agencies between the two communities provide drug and alcohol abuse counseling. Three of these programs are located in Pawtucket and four are located in West Warwick. It may be possible to integrate some of these programs with programs designed to address other, related risk behaviors. A program designed to enhance youths' self esteem and resistance to negative peer pressure could be combined with one of the four drug and alcohol counseling programs in West Warwick. This type of inter-risk factor integration could strengthen the quality, effectiveness, and efficiency of service provision in these communities.

Public schouls may also be key institutions which need to be integrated into the fabric of community service provision. Presently, schools are failing to provide for the complex health, social, and cognitive needs of youth (Lerner, 1995). This failure, according to Dryfoos (1994) and Lerner (1994) is derived in part from three interrelated problems;

- first, schools are not adequately addressing the high-risk behaviors engaged in by today's youth 
- second, the increasing prevalence of poverty is both diminishing the resources available to schools and adding to the stress of the students and parents,

- finally, schools are not integrated into the community in regards to other youth serving programs and institutions.

It should be noted that public schools were never intended to offer these kinds of social services and have not failed in fulfilling their task of educating youth. The concept of full-service schools represents the integration of these services with public schools.

"Such schools involve, then, in a fully integrated manner: (a) community-wide, multiagency collaborations, (b) involving a full range of social services (e.g., health centers, vocational guidance and career development programs, and counseling services), which are (c) embedded within schools but are administered by the collaborating nonschool agencies; and use (d) citizen input and volunteerism" (Lerner 1995, p.95).

The Child Opportunity Zone (COZ) concept, currently being applied at the Cunningham Elementary School in Pawtucket, may be a step toward this type of integrated service provision. The $\mathrm{COZ}$ offers programs ranging from day care to adult education to the residents of the Woodlawn neighborhood in Pawtucket. Although, the services offered are not as diverse as those found in full-service schools it is an attempt at integrated service provision.

Engage in Participatory-Normative Evaluation (DICE Model) 
"Promoting positive individual and social development and change through the incorporation of participatory evaluation into program design and implementation is precisely what is considered within a developmental contextual view of evaluation" (Lerner 1995, p.84) There are three interrelated characteristics which participatorynormative programs share. First, the process of building programs is asset based. "The programs should start with what is in the community-the capacities of the residents and of the programs, agencies, and other institutions based in the area-not with what is absent" Lerner 1995, p.87). Second, the agenda's of the various programs are based on the values, and problem solving capacities of the local residents, associations, and institutions. A qualitative understanding of the particular meaning system of each community should be held by the researcher so that the programs can be guided in the direction desired by the clients. Finally, positive relationships between local residents, local associations, local institutions are promoted so that a collaborative, caring communities can be created (Lerner, 1995).

The DICE model is an approach for evaluating ways in which programs can be enhanced by focusing on the particular coniext of the communities in which they are applied. The model focuses on the stakeholders' perspectives of the regarding the direction programming should take in their community. The importance of co-learning between members of the community and outreach programmers is vital to the DICE model process. An organization such as Cooperative Extension can assist community agencies by providing expertise in the area of evaluation methodology, screening, and 
assessment. However, Extension faculty must learn from community members about what development in their particular community context means. According to Lerner, "They must network with community members to learn (a) who are the people whose voices must be included as part of the program and its evaluation, and thus (b) the issues that the community wants to have addresses and that are seen as the most salient. Finally, faculty must learn what specific evaluation tools are necessary and appropriate to deploy or to develop in the community" (Lerner 1995, p. 88).

The goal of DICE programs then, are for outreach professionals to work collaboratively with the relevant stakeholders to identify and describe problems which exist in the community, articulate program goals, and determine the kinds of questions the stakeholders want to have answered. The strongest and most appropriate evaluation design for each community can then be formulated (Lerner, 1995).

Data collection and analysis must be multifaceted given the vast array of issues and methods that may be used in each community. A key goal of any development-incontext evaluation (DICE) is to obtain interpretation of the day-to-day realities of the people, programs, and contexts involved in the program. "The participants themselves are the experts of the meaning of development in their community context; they are the source of the important interpretations of the data" (Lerner 1995, p.89). Through collaborating with the community in the interpretation of the data evaluators and stakeholders can determine whether the program is appropriate for the needs of the community. If so, the stakeholders will be able to make judgments about the features of the program that should be maintained, revised, or eliminated. If not, the 
stakeholders will be able to better clarify to the evaluators what sort of information they need to make such judgments. In either case the ability of the stakeholders to make better informed decisions regarding community programming will be enhanced (Lerner, 1995).

The increased capacity of the community stakeholders resulting from this collaborative evaluation can eventually result in enhance program sustainability. "The capacity of youth, families, and other community stakeholders to enact and sustain desired programs will likely be furthered significantly as a consequence of (a) the community's enhanced abilities in program design, implementation, and evaluation; (b) community members' increased knowledge of themselves, gained through the data that they themselves helped to collect and analyze; and (c) the community's increased experiences with successful decision making, that is, with what is a constant part of the process of participatory evaluation procedures such as those involved in the DICE model" (Lerner 1995, p.90-91).

The following points summarize what evaluators following the DICE model must do:

- "Work with the community members to identify the problems or issues to which the program will be directed

- Engage the members of the community in (a) the planning of the evaluation; (b) decisions about the nature of the information sought about the program; (c) the collection of relevant data; and (d) the interpretation of the information derived from the evaluation 
- Collaborate with the community in the use of the information derived from the evaluation, for example, in the execution of any "mid-course" corrections deemed necessary to enhance program effectiveness and/or in the identification of any changes that have resulted in the nature of the problem that led to the initiation of the program" (Lerner 1995, p.91).

The evaluation is predicated on attention to the diversity which exists within a specific community, to the specific goals, values, and meaning systems that are present in the community and shape local programs. Recognition of the importance of such diversity is critical to the design of effective prevention programs (Lerner, 1995).

Further Integrate Cooperative Extension into the Communities

Collaborative evaluation can be more effective when university outreach, such as that provided through Cooperative Extension, is incorporated into the development of community-based social service programs. "Developmental contextualism stresses that the problems facing the youth of America require an integrated set of activities by the members of our nation's research and extension communities" (Lerner 1995, p. 111). It has been observed by researchers such as Schorr (1988) and Dryfoos (1990) that many effective youth programs have not been sustained because members of the community lack the capacity to maintain the programs once the outside programming/assistance has been withdrawn (Lerner, 1995). The expertise of Cooperative Extension in regards to "best practices" observed for various programs 
can be used to help community service providers to design the most appropriate and sustainable program possible. In other words, the experience gained by Cooperative Extension in interfacing with various communities can be used to inform service providers as to what has and has not worked. "This information may allow public policy-makers, community organizers, researchers, and others to better use their money and time developing or replicating successful programs" (Lerner 1995, p.113). Information about what works in specific communities such as Pawtucket and West Warwick could be cataloged and disseminated to the appropriate community agencies through Cooperative Extension and specifically by the Children, Youth \& Families Issue Group.

This approach to knowledge application underscores the need for a sustained commitment to a campus-community partnership (Lerner, 1995). Further integration between local universities and colleges and the community's in which they reside has the potential to simultaneously enhance both effectiveness of social service provision and the public perception of institutions of higher learning.

\section{Conclusions}

Pawtucket and West Warwick, Rhode Island are dynamic communities with different values, assets, programming needs, and service providers. However, though these communities have their own very different contexts they can both benefit from the same type of collaborate evaluation practices outlined throughout this report. 
Enhanced client participation in may help service providers to realize the specific motivations, interests, and values of their clientele. Client involvement in the evaluation and decision making process can empower individuals to take control over programs which are in place in their communities. Such empowerment can serve to enhance the sustainability and the effectiveness of social service programs in any Rhode Island Community.

The separate focus on individual risk behaviors and problems may detrimental to the effectiveness the various community services. An integrated, case management approach to services may be a more effective strategy for preventing the development of risk behaviors in Rhode Island youths. The collaboration of service providers may not only be more effective but more cost efficient.

The use of the development-in-context (DICE) model for evaluating ways in which programs can focus on the particular context of the communities in which they are applied should be considered by local service providers. The model focuses on the stakeholders' perspectives of the regarding the direction programming should take in their community. The importance of co-learning between menbers of the cummunity and outreach programmers is vital to the DICE model process. Collaborative evaluation can be more effective when university outreach, such as that provided through Cooperative Extension, is incorporated into the development of communitybased social service programs.

The Children, Youth \& Families Issue Group may be the most appropriate conduit for suggesting the use of the strategies recommended by this report to local 
service providers in Rhode Island communities. The programmatic mission of the Children, Youth and Families Issue Group includes the following goals;

- Provide current, research based information, technical assistance and educational programming for children, youth, and families and groups focused on the development of human potential, family well-being and leadership development skills.

- Address youth and family issues by initiating educational outreach programs and networking, to foster cooperation, partnerships, and coalitions.

- Research, create, nurture, support and evaluate children, youth and family development and building human capital programs of the URI Cooperative Extension with the goal of improving the life and environment of at risk children, youth and families including,

-School age child care and after school education

-Coalitions which support community programming for high risk youth

-Development of literacy and technological literacy in youth at risk

-Parent education and parenting skills to support family life

- Develop skills and competencies to assist children, youth and families in becoming self-sufficient and productive citizens.

The dissemination of the strategies suggested in this report to local service providers in Rhode Island by the "Issue Group" is consistent with the groups stated mission. The theories presented in this report are applicable to any at-risk community. Service providers and outreach professionals must respect the particular contexts of the 
communities in which they work. As Dr., Lerner has stated; The participants themselves are the experts of the meaning of development in their community context;

they are the source of the important interpretations of the data (Lerner 1995, p.89). 


\section{REFERENCES}

Ahlburg, D.A., \& De Vita, C.J. (1992). New Realities of the American Family. Population Bulletin, 47(2), 1-44.

Allison, K. W. (1993). Adolescents living in "non-family" and alternative settings. In R.M. Lerner (Ed), Early adolescence: Perspectives on Research, Policy, and Intervention. (pp.37-50).

Hillsdale, NJ: Lawrence Erlbaum.

Allison, K.W., \& Lerner, R.M. (1993). Integrating research, policy, and programs for adolescents and their families. In R.M Lerner (Ed), Early adolescence: Perspectives on Research, Policy, and Intervention. (pp.17-23). Hillsdale, NJ: Lawrence Erlbaum.

Ames, C., \& Ames R. (Eds).(1989). Research in motivation in education: Vol 3. Goals and Cognition 's, New York: Academic Press.

Anastasi, A. (1958). Heredity, environment, and the question, "how?" Psychological Review, 65, (pp. 197-208).

Baca Zinn, M., \& Eitzen, D.S. (1993). Diversity in Families. (3rd ed). New York: Harper Collins College.

Baltes, P. B. (1968). Longitudinal and cross-sectional sequences in the study of age and generation effects. Human Development, 11, 145-171.

Baltes, P.B. (1987). Theoretical propositions of life-span developmental psychology: On the dynamics between growth and decline. Developmental Psychology. 23, 611-626.

Belsky, J., Lerner, R.M., \& Spanier, G.B. (1984). The child in the family. Reading, MA: Addison-Wesley.

Birkel, R., Lerner, R.M. \& Smyer, M.A. (1989). Applied developmental psychology as an implementation of a life-span view of human development. Journal of Applied Developmental Psychology, 10, 425-445.

Brim, O.G., Jr., \& Kagan, J. (Eds.). (1980). Constancy and change in human development.

Cambridge, MA: Harvard University Press.

Bronfenbrenner, Urie. 1977. Toward an experimental ecology of human development. American Psychologist, 32, 613-531. 
Bronfenbrenner, Urie. 1979. The ecology of human development. Cambridge, MA. University Press.

Bronfenbrenner, Urie. 1983. The context of development and the development of context. In R.M. Lerner (Ed.), Developmental psychology: Historical and philosophical perspectives (pp. 39-83). Hillsdale, New Jersey: Lawrence Erlbaum.

Bronfenbrenner, Urie. 1986. A generation in jeopardy: America's hidden family policy. Testimony presented at a hearing of the Senate Committee on Rules and Administration on a Resolution to establish a Select Committee on Families, Youth and Children.

Bronfenbrenner, Urie. 1989. Early childhood education programs: Needs and dangers Testimony presented at a hearing of the Joint Economic Committee of the House and Senate of the United States.

Carnegie Corporation of New York. 1992. A matter of time: Risk and opportunity in the nonschool hours. Carnegie Council on Adolescent Development. Waldorf, MD

Center for the Study of Social Policy. 1995. Kids Count Data Book. Washington, DC.

Dryfoos, J.G., 1990. Adolescents at risk: Prevalence and prevention. New York: Oxford University Press.

Dryfoos, J.G. 1990. Community Schools: New institutional arrangements for preventing high risk behavior. Family Life Educator, Summer, 4-9.

Hamburg, D.A. 1992. Today's children: Creating a future for a generation in crisis. New York: Times Books.

Lerner, R.M. 1995. America's youth in crisis: Challenges and options for programs and policies. Sage Publizations: London.

Little, R.R. 1993. What's working for today's youth; The issues, the programs, the learning's. Michigan State University, East Lansing.

McKnight, J.L. \& Kretzmann, J.P. 1993. Mapping Community Capacity. Michigan State University Community \& Economic Development Program News, pp. 1-4.

Schneirla, T,C., 1957. The concept of development in comparative psychology. In D.B. Harris (Ed.), The concept of development. pp. 78-108. Minneapolis: University of Minnasota Press.

Schorr, L.B., 1992. Effective programs for children growing up in concentrated poverty. In A.C. Hutson (Ed.), Children in poverty: Child development and public policy. pp. $260-$ 281. Cambridge, UK: Cambridge University Press. 